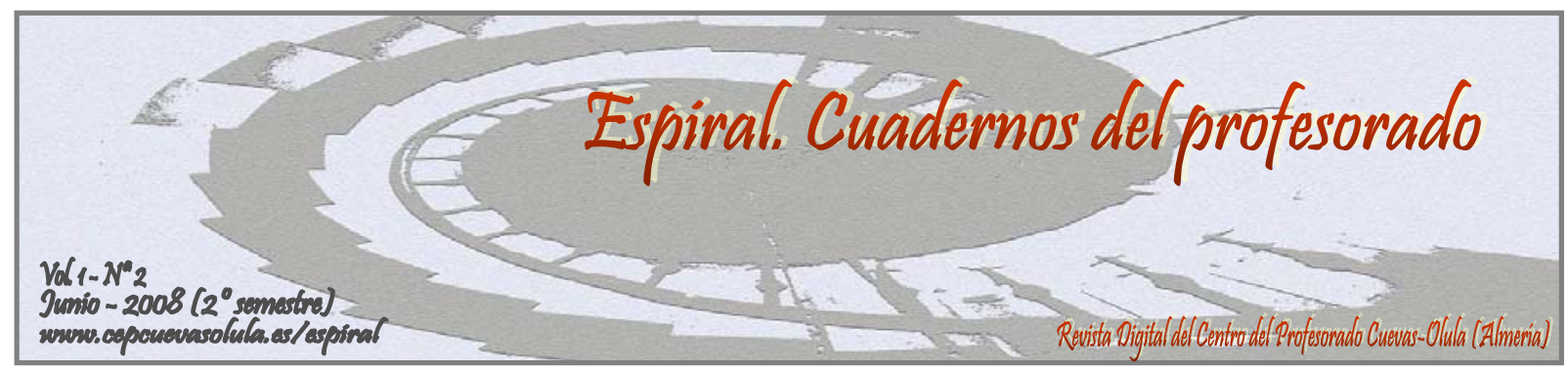

\title{
APROXIMACIÓN A UNA INSTITUCIÓN ESCOLAR DECIMONÓNICA: EL COLEGIO DE NUESTRA SEÑORA DEL CARMEN DE CUEVAS DEL ALMANZORA (ALMERÍA)
}

\author{
Enrique Fernández Bolea
}

\author{
Profesor de Lengua Italiana en la E.O.I. de Macael (Almería)
}

Enviar correspondencia a: enriquebolea@hotmail.com

\begin{abstract}
RESUMEN: Los convulsos inicios del siglo XIX mostrarán un sistema de enseñanza que apenas si se había renovado en los últimos trescientos años. Aquellos primeros y efímeros intentos legisladores protagonizados por las Cortes de Cádiz en 1812, dedicando su capítulo IX a la instrucción pública, o la primera Ley General salida del empeño del ministro de Fomento Claudio Moyano en 1857 no cambiarían en exceso el estado de decadencia, de postración, que arrastraban los niveles de primera y segunda enseñanza en España. La burguesía, esa nueva clase que se hará con el poder desde la muerte de Fernando VII, se entregará tanto al fomento de una primera enseñanza destinada a todos los sectores de población, incluidos los más humildes y populares, como de una segunda que garantizase esa formación sólida que precisaban los cachorros de esta nueva clase, futuros rectores de los destinos de la patria. La emergente burguesía cuevana no iba a ser una excepción en esa tendencia y se constituirá en la principal responsable de la fundación y continuidad del Colegio Nuestra Señora del Carmen, uno de los más importantes centros educativos del XIX almeriense tanto en su primera etapa como en la regida por la orden de los Dominicos.
\end{abstract}

Palabras clave: Cuevas del Almanzora, primera y segunda enseñanza, burguesía, dominicos.

ABSTRACT: The shocking early nineteenth century will show a school system that barely had been renovated in the last three hundred years. Those early attempts legislators and ephemeral feature staredby the Court of Cadiz in 1812, dedicating his chapter IX to public education, or the first exit General Law produced by the commitment of the minister of Public Works Claudio Moyano in 1857 would not change over the state of decay, prostration, which dragged the first and second levels of education in Spain. The bourgeoisie, this new class that will get the power since the death of Fernando VII, will be delivered both to promote an early education for all segments of population, including more humble and popular, and a second to ensure that solid training requiring thy pupils of this new class, future guiding the destiny of the motherland. The emerging bourgeoisie from Cuevas would not be an exception in this trend and will constitute itself main responsible of the foundation and continuity of the College of Our Lady of Carmen, one of the most important schools of the nineteenth Almeria both in its first phase and in the governed by the order of Dominicans.

Key words: Cuevas del Almanzora, first and second lesson, bourgeoisie, Dominicans. 


\section{1.- LAICOS Y FRAILES FRANCISCANOS, MAESTROS DE PRIMERAS LETRAS $Y$ LATINIDAD.}

Transcurrían, miserables y agónicos, los años centrales de la guerra contra el francés y la población aún arrastraba el funesto recuerdo de la epidemia de fiebre amarilla que con ella, como con tantas otras localidades de la costa mediterránea, se había cebado a lo largo de $1812^{1}$. En los años posteriores, las actas capitulares generadas por el cabildo aludirán a las consecuencias de aquella terrible "peste", a la sangría demográfica que provocó en una comunidad demasiado expuesta, a las medidas de la autoridad municipal en evitación de nuevos brotes y, sobre todo, a una psicosis colectiva que se había apoderado de unas gentes atenazadas por el pavor ante la posibilidad de que aquella calamidad pudiera volver a repetirse ${ }^{2}$. Sin embargo, entre las precauciones adoptadas por la Junta de Sanidad local y la aprobación de las partidas de granos y otros alimentos con destino al avituallamiento de las tropas nacionales acantonadas en Lorca, medidas excepcionales que respondían a circunstancias vitales extremas, la cotidianidad se abría paso a través de pequeños pero significativos gestos administrativos que indicarán -como sucede en períodos de conflicto y desastre- una búsqueda de normalidad que otorgue un poco de cordura a tanta desgracia, a tanto espanto, a tanta dificultad. El 17 de julio de 1813, José Lledó, maestro de primeras letras ${ }^{3}$ de

\footnotetext{
${ }^{1}$ Hasta que no se lleve a cabo una investigación exhaustiva sobre este episodio histórico de consecuencias tan funestas y desgarradoras para nuestra comarca, deberemos conformarnos con el relato que, sobre las repercusiones de la fiebre amarilla en la localidad de Turre, nos ofrecen Grima Cervantes, J. (coord.), Alarcón, A. \& Alarcón, J. (1996) en su libro Turre. Historia, cultura, tradición y fotografía (pp. 61-62). Turre: Arráez Editores.

2 Actas capitulares, 1813 y 1814, Archivo Municipal de Cuevas del Almanzora (AMCA en nuevas citas), libs. 81 y 82.

${ }^{3}$ Hasta estos inicios del siglo XIX, y desde hacía varias centurias, se venía desarrollando lo que los contemporáneos llamaron escuela de primeras letras, en donde esencialmente se impartía la enseñanza de la doctrina cristiana, una iniciación a la lectura, las cuatro reglas básicas de aritmética y la enseñanza de la escritura a través de muestras o copiados. En cuanto a los maestros de primeras letras de la época, su principal objeto era el de enseñar a escribir, y su formación no sobrepasaba los dos años de asistencia a una escue-
}

la villa, elevará instancia a la Diputación Provincial de Granada suplicando un aumento de su dotación económica ${ }^{4}$, porque la que en aquel momento disfrutaba -100 ducados- ni siquiera lograba cubrir sus necesidades mínimas al destinar "la mayor parte de ella al alquiler de la casa para la enseñanza por no haberla de oficio"; en su favor argumentaba el prestigio que había acumulado en el desarrollo de su labor docente, pues "los progresos de los niños han llamado la atención del Pueblo", lo que no había resultado suficiente para convencer al Ayuntamiento de que le elevase la pensión y por ello, "ante la dura precisión de quedar expuesto a la necesidad", solicitaba de la institución provincial la emisión de una orden que obligase al Cabildo a abonarle "otros cien ducados [...] para continuar sin apuros su ministerio y no ser sumergido en la miseria". Para el 26 de agosto, el Ayuntamiento acordará el cumplimiento de la orden que una semana antes había recibido de Granada, aunque con alguna limitación:

"[...] la instancia que se hace por parte de Dn Josef Lledó, maestro de primeras letras de esta villa sobre el aumento de su renta de dotación de Propios es arreglada como los motivos en que la funda, pero atendiendo al escaso producto de dichos propios, por cuya causa se hallan retrasados los pagos de rentas que sobre ellos están consignados a favor de los demás empleados públicos, sólo puede reducirse dicho aumento a la cantidad de cincuenta ducados más que, unida con la asignación anterior, asciende a ciento cincuenta ducados...,"

El valor de la reclamación precedente radicará en la información que se desprende sobre la dependencia administrativa de aquel incipiente sistema escolar en los inicios del siglo

la, exigiéndoseles para ejercer, además de ciertos conocimientos de Doctrina Cristiana, saber leer y escribir. La Cortes de Cádiz, en su título IX, dedicado a la Instrucción Pública, disponían la existencia de una escuela primaria por cada 500 habitantes, estableciendo unos objetivos mínimos: leer con sentido, escribir con claridad y buena ortografía, reglas elementales de aritmética, dogmas de religión y principales derechos y obligaciones del ciudadano.

${ }^{4}$ Instancia de José Lledó a la Diputación Provincial de Granada, Actas Capitulares, 1813, AMCA, lib. 81.

5 “Cumplimiento”, Actas Capitulares, 1813, AMCA, lib. 81. 
XIX, así como en la evidencia de las profundas deficiencias que lastraban unos recursos educativos tan básicos como escasos. La Diputación Provincial, como órgano superior, y el Ayuntamiento, más cercano a la realidad cotidiana, poseían todas las competencias sobre la organización, inspección y dotación presupuestaria de un servicio caracterizado por la precariedad de medios. Claro ejemplo de estas funciones asumidas por el Municipio es el acuerdo de 24 de junio de 1820 autorizando a su regidor, José Manuel Campoy;

"encargado por este Ayuntamiento para la visita de las Escuelas de enseñanza, asistido del presente escribano, pase a la escuela del don José Lledó y observe la que presta a los niños, así en el leer, como en escribir y contar, $y$ en los rudimentos de la Doctrina, haciéndole al maestro ejercitar estas actuaciones, como igualmente la enseñanza que se halla a cargo del religioso Fr. José Robles...”“

Un año antes, el 21 de mayo de 1819, el cabildo, asumiendo sus funciones de inspección sobre las escuelas públicas de la localidad, interviene en un caso de malos tratos a un niño por parte de su "religioso maestro de primeras letras"; como había denunciado su padre, Felipe Soler, al alcalde mayor, fue tanta la saña y tan desproporcionado el rigor empleados por aquél que la pobre criatura estaba postrada en cama "con diferentes golpes en su cuerpo, y especialmente en la barba y boca, habiendo derramado porción de sangre”. No obstante, no era la primera vez que al fraile se le había ido la mano, tal era la pasión que derrochaba a la hora de aleccionar a sus discípulos, pues "este suceso ya se había verificado con otros niños”. El informe emitido por el facultativo -del que merece extractar la descripción de las lesionesno arroja la más mínima duda sobre la brutalidad empleada por el docente:

"[...] viese a su hijo, maltratado del castigo que había recibido del religioso maestro de escuela, y en efecto habiendo reconocido dicho niño de edad de unos ocho a nueve años, le halló en cama, acometido de una fuerte horripilación

\footnotetext{
6 “Ayuntamiento constitucional de Cuevas del día 24 de junio de 1820”, Actas Capitulares, AMCA, lib. 88.

7 “Ayuntamiento del 21 de mayo de 1819”, Actas Capitulares, AMCA, lib. 87.
}

[sic] ocasionada de la pasión de ánimo que había sufrido. Inspeccionándole los sitios en que había recibido los golpes, echó de ver una grande esprimosis [sic] bajo de la barba y varias en los brazos, la de la barba su infarto llegó a causarle inflamación de dicho sitio y se extendía a la mayor parte del cuello. Las demás las juzgó por más leves...”.

El Ayuntamiento, competente a la hora de adoptar los correctivos frente a una actitud tan deplorable $^{8}$, de inmediato elevará oficio al reverendo padre guardián del Convento franciscano de San Antonio en busca de la reprobación que debía recaer sobre aquel miembro se su congregación, aunque como veremos enseguida la sanción -si es que así puede calificarse- distaría mucho de un verdadero escarmiento:

"Disponga por ahora se corrija al
mencionado religioso maestro de primeras letras para que en el castigo de los niños no exceda a los límites que le prescriben la humanidad y las reglas con que debe portarse todo maestro de primeras letras, pues de lo contrario o en el caso de verificarse otra queja o caso de los que se han presentado ya, el Ayuntamiento tomará las serias providencias que estime convenientes para el remedio de los males que son consiguientes y calmar los clamores del público".

A la obligación de dotar económicamente a los maestros empleados en las escuelas públicas y a esa labor de inspección que queda testimoniada mediante los ejemplos precedentes, sumaba el Ayuntamiento su potestad para promover y autorizar, en su caso, cualquier oferta educativa que se creyese oportuna para la formación de determinados sectores de la localidad. Valga como muestra el acuerdo adoptado por la institución en pleno sexenio absolutista con el fin de instalar en la ermita de

\footnotetext{
${ }^{8}$ Se debería hacer notar que en aquel momento los castigos corporales en la escuela eran socialmente aceptados, con excepción de aquellos salvajes y despiadados que ponían en grave riesgo la propia integridad de los alumnos. A esta última clase se ajustaría el que se acaba de referir.
} 


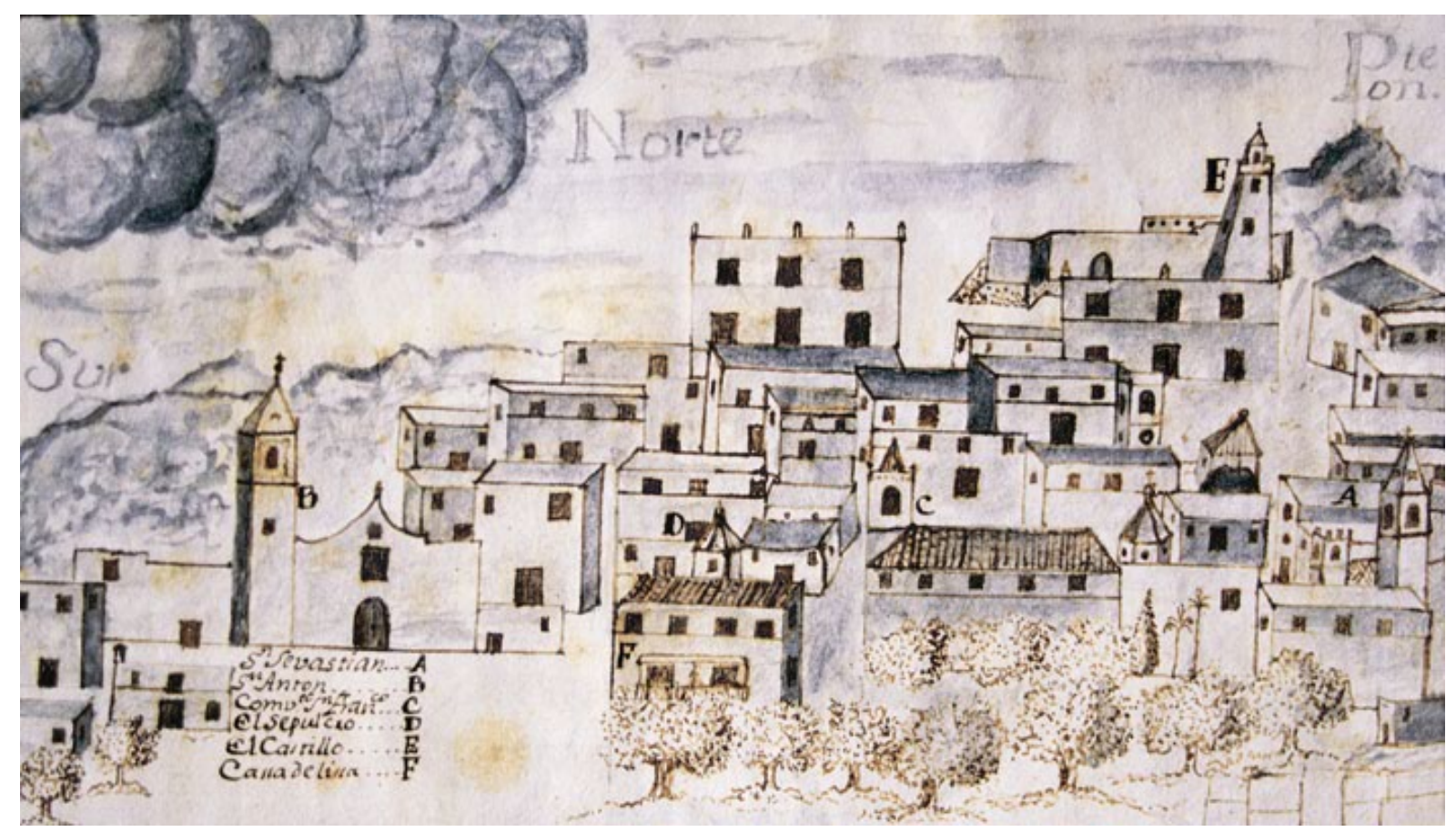

Figura 1.- Recreación de la fisonomía urbana de la villa a mediados del siglo XVIII. Media centuria después en poco habría cambiado Cuevas su semblante. En la parte inferior derecha, marcado con la letra C, se distingue el convento franciscano de San Antonio de Padua. (Catastro del Marqués de Ensenada / Archivo Municipal de Cuevas del Almanzora).

San Sebastián una cátedra dedicada a la enseñanza de Gramática Latina, al considerar esta materia altamente beneficiosa para los intereses formativos de la juventud local ${ }^{9}$. Para cubrir el puesto se recurrirá al único centro que, por entonces, podía proporcionar el especialista requerido, de ahí que el 30 de enero de 1817 el padre guardián de San Antonio, fray Antonio Torrenas, envíe una providencia al Ayuntamiento en la que se le notificaba haber ordenado al licenciado en Artes Joseph Pérez su incorporación inmediata a la enseñanza de aquella disciplina ${ }^{10}$. Dos años más tarde, debido al fallecimiento de este maestro de Latinidad, la autoridad municipal se entregará con celo a su sustitución y, aprovechando la estancia en Cuevas del reverendo padre provincial de San Francisco, solicitará de éste el nombramiento de otro individuo de su congregación capacitado para ocupar la plaza que había resultado vacante,

\footnotetext{
${ }^{9}$ Durante la etapa absolutista (1814-1833) -con la breve excepción del Trienio Liberal- Fernando VII recuperó la estructura educativa del Antiguo Régimen, es decir los estudios bajo la denominación de Segunda Enseñanza, previos a los universitarios, se redujeron a los de Latinidad y Humanidades.

10 “Providencia”, Actas Capitulares, 1817, AMCA, lib. 85.
}

responsabilidad que recaerá en fray Antonio Martín, quien recibe la orden de su superior cuando ejercía como predicador conventual en la villa de Vélez Rubio ${ }^{11}$. De este modo, el 28 de abril de 1819 el padre Martín, que acaba de arribar a Cuevas, manda un comunicado al gobierno de la villa donde expresa su disposición a ejercer las funciones que se le han encomendado y queda a la espera de que se le notifique el día de inicio de las clases, así como la pensión con que cada uno de los alumnos debía contribuir al mantenimiento de la cátedra.

Suficientemente demostrada queda la incursión de los franciscanos en las labores educativas que Cuevas precisaba durante aquel tumultuoso primer cuarto del XIX, e igualmente constatada hallamos su participación en los distintos niveles que entonces se impartían, desde las primeras letras hasta la específica enseñanza del Latín. De corroborarlo se ocupará también el desconocido autor de un artículo, inserto en las páginas de El Minero de Almagrera que aludía a la situación de la localidad con anterioridad al descubrimiento del filón de plata del Jaroso en 1838, refiriendo, entre otras muchas cosas, la

\footnotetext{
11 “Ayuntamiento de Cuevas del 24 de abril de 1819”, Actas Capitulares, AMCA, lib. 87.
} 
dedicación de los frailes franciscanos a los pormenores de la enseñanza y considerando aquel centro religioso como el único de la población de donde podía irradiar la sabiduría; y es que entre los veinte frailes que en circunstancias normales integraban aquella comunidad destacaban "eminentes canonistas y moralistas, y elocuentes oradores, existiendo en el convento una biblioteca con más de 3.000 volúmenes, y aulas en las que se enseñaban la filosofía y el derecho, de las que salieron muchos y aventajados discípulos"12.

Así estuvieron las cosas hasta la exclaustración de la congregación franciscana el 5 de septiembre de 1835. Es cierto que las leyes desamortizadoras de Mendizábal afectaron al convento de San Antonio de Papua (figura 1), si bien este establecimiento religioso nunca fue enajenado, pasando a ser administrado por la Intendencia de la Provincia de Almería para los Bienes Desamortizados. Las antiguas dependencias conventuales se sometieron desde los primeros momentos de su desamortización a un régimen de alquiler en el que el Ayuntamiento actuaba como intermediario entre la Intendencia y los inquilinos ${ }^{13}$. Muy diversos fueron los usos a los que los arrendatarios destinaron las antiguas celdas y espacios comunes del convento: desde cuadras y almacenes para la acumulación de enseres, hasta teatro ${ }^{14}$ y sede de alguna institución educativa. Pues sí, el presbítero Miguel Soler Flores (figura 2), uno de esos clérigos favorecidos por la fortuna al haber sido partícipe con dos acciones de la portentosa sociedad minera Carmen y Consortes que promoviese su padre, Miguel Soler Molina,

12 “Desagravio", en El Minero de Almagrera, n 930931, 27 de junio de 1893, pp. 4-5. Este artículo supuso la reacción del veterano medio escrito contra otro que, con el título "Tres fechas”, acababa de aparecer en las páginas del también periódico local El Desagüe, al que acusará de irreflexión y ligereza a la hora de permitir la publicación de determinados contenidos que vilipendiaban, aireando falsedades, la imagen histórica de Cuevas.

${ }^{13}$ Sobre el destino de los espacios conventuales tras la exclaustración, se conserva un sustancioso Expediente sobre cobranza de un resto de alquiler de las habitaciones del ex-convento de San Francisco de esta villa, Expedientes, 1845, AMCA, leg. 497.

14 Véase Fernández Bolea, E. \& Flores García, A. (2007). El teatro Echegaray de Cuevas del Almanzora, templo burgués de ocio y cultura. Axarquía, 12, p. 126. solicitará en 1842 la preceptiva autorización para instalar en el ex-convento de San Antonio un colegio de segunda enseñanza bajo la denominación de Purísima Concepción. Fue aquel establecimiento el primero de sus características en la localidad $^{15}$, obteniendo desde sus comienzos prestigio y renombre al quedar incorporado a la Universidad Literaria de Granada por Real Orden de 12 de agosto de aquel año. Será en octubre cuando el presbítero fundador, que ejercerá de rector-director, y los dos catedráticos que integraban su claustro de profesores afronten la enseñanza de las materias programadas: gramática general, física experimental y general, gramática latina, ética, teología natural, ideología, lógica y matemáticas ${ }^{16}$. Por aquellas aulas pasarían los vástagos de esas familias que, en tan sólo cuatro años, han protagonizado un vertiginoso enriquecimiento como consecuencia de los ingentes beneficios que las minas de Almagrera les han proporcionado; a medida que incrementaban su hacienda y patrimonio han ido modificando sus costumbres, diversificando $\mathrm{y}$ aumentando sus necesidades, y exigiendo para sus descendientes una formación educativa a la que ellos no habían tenido acceso. Es en este contexto de desaforado crecimiento económico, de transformación de usos sociales, en donde

${ }^{15}$ De extraordinariamente temprana puede considerarse la fundación de este centro educativo, ya que no habían transcurrido ni seis años del Plan del Duque de Rivas, de 1836, sobre el que se fundamentaría la reordenación de la enseñanza que se llevó a cabo en 1845 por la que se reconocía la instrucción secundaria elemental y de ampliación, al tiempo que se ofertaban dos secciones, una de Letras y otra de Ciencias.

${ }^{16}$ Lo hasta aquí referido sobre el colegio Purísima Concepción es rescatado por Miguel Flores GonzálezGrano de Oro, cronista de Cuevas y correspondiente de la Real Academia de la Historia, para formar parte de su opúsculo Las instituciones escolares de Cuevas del Almanzora (Almería), Cuevas, Imprenta de Campoy, 1932; con posterioridad los mismos datos quedarán incluidos en la segunda entrega de la serie de tres artículos que publicó el autor en el periódico local El Censor, $\mathrm{n}^{\circ} 85$, de 30 de noviembre de 1932, con el título ya mencionado de "Las Instituciones escolares en Cuevas del Almanzora (Almería)”. Ahora bien, la fuente de que se nutre nuestro cronista es el Diccionario Geográfico-Estadístico-Histórico de España y sus posesiones de ultramar de Pascual Madoz, en su edición 1845-1850, ya que los datos oreados por Flores son los mismos que aporta el corresponsal del geógrafo en la entrada "Cuevas de Vera”. 
habría que situar la precoz aparición -para una todavía pequeña entidad de población perteneciente a una de las provincias más aisladas y marginales de la geografía españolade un establecimiento de segunda enseñanza vinculado, además, a una importante universidad.

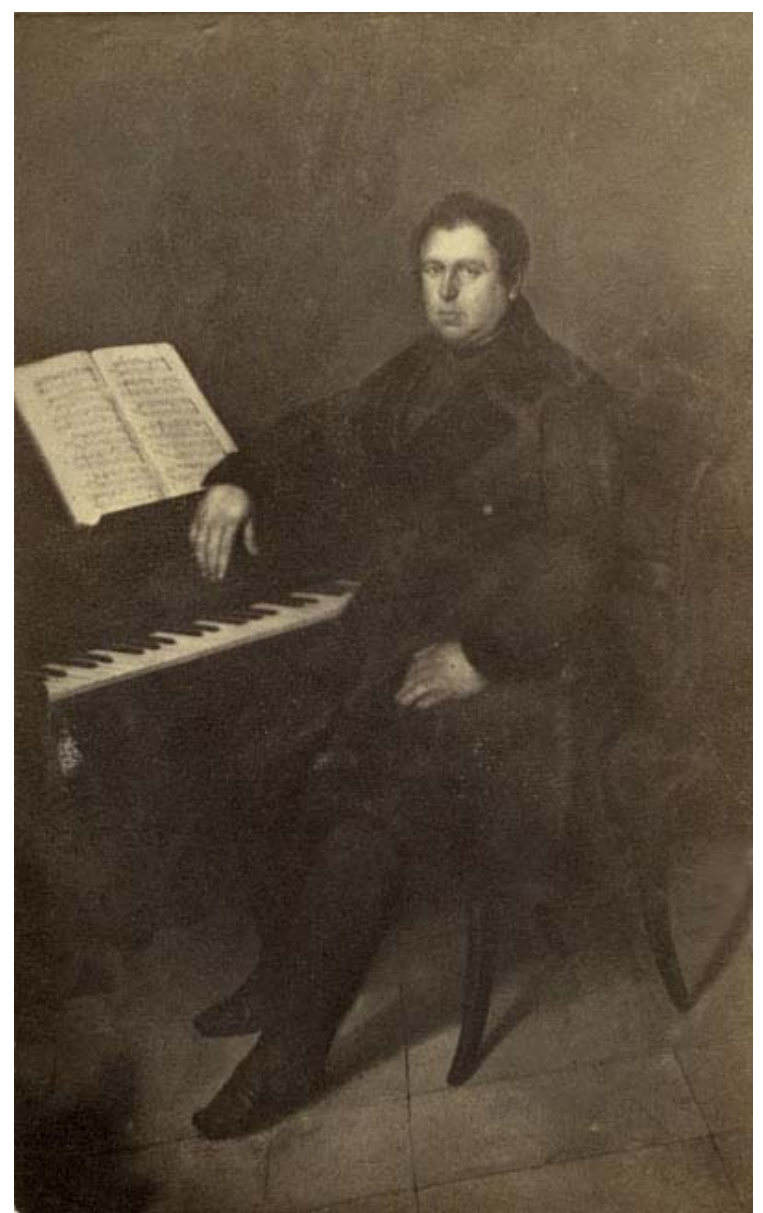

Figura 2.- El presbítero Miguel Soler Flores, fundador en 1842 del colegio de segunda enseñanza Purísima Concepción. Fotografía de época, posiblemente del lorquino José Rodrigo, de un lienzo del pintor Andrea Giuliani. Hacia 1845. (Col. Amalia Soler).

Sin embargo, la revisión de la documentación conservada ayuda a extraer una primera conclusión sobre la historia de este colegio: su existencia -al menos en la ocupación de los locales conventuales- fue bastante efímera. Ello se desprende, en primer lugar, de la consulta del "Estado general de lo cobrado y débito en el aprovechamiento de San Francisco de Cuevas"17

\footnotetext{
${ }^{17}$ En Expediente sobre cobranza de un resto de alquiler de las habitaciones del ex-convento de San Francisco de esta villa, AMCA, leg. 497. Desde estos años en adelante la denominación de San Antonio de Padua
}

de septiembre de 1844, ya que entre los incluidos en el largo listado de arrendatarios de estas dependencias conventuales no hay constancia ni del nombre del presbítero Soler Flores ni tan siquiera de la existencia, como habría sido preceptivo, del colegio Purísima Concepción. Cabría la posibilidad de que el impulsor de este establecimiento docente hubiese decidido trasladarlo a otros locales o bien que estuviese exento del pago de alquiler en atención a la naturaleza social del servicio que prestaba. Ahora bien, lo que a continuación expondremos, procedente de otros testimonios documentales, más bien apuntará hacia una temprana desaparición de aquel centro de enseñanza, pues de lo contrario no se entendería la insistencia del Ayuntamiento en la reclamación de un servicio educativo que ya existía en la localidad.

Mediado el mes de abril de 1843, el Gobierno Eclesiástico del Obispado de Almería pone en conocimiento de los ayuntamientos de su Diócesis una orden del Ministerio de Gracia y Justicia con la que pretendía clarificar el grado de utilización de los edificios religiosos desamortizados, es decir, buscaba "fijar de una vez el número de iglesias de los Monasterios y Conventos suprimidos que [debiesen] conservarse abiertos para el mejor servicio espiritual de la Diócesis"18. El Ayuntamiento, tras una bien argumentada defensa de la necesidad de mantener abierto al culto el templo anexo al convento como ayuda de parroquia, abogará en su respuesta por que esas mismas intenciones de búsqueda de utilidad se extiendan al resto de los locales conventuales, destinándose en el futuro al beneficio de la instrucción pública:

"[...] en él pudieran plantearse las clases de primera y segunda enseñanza de que tanta necesidad hay para la ilustración y civismo de estos vecinos, y que se desarrollen en esta población, célebre ya por sus riquezas y por el gran concurso de gentes, establecimientos de enseñanza que la generalizasen hasta entre los más infelices, librándose con esta medida los padres del sentimiento de tener que alejar $a$ sus hijos y sus capitales a puntos

irá cayendo en desuso en beneficio de la de San Francisco.

${ }^{18}$ Oficio del Gobierno Eclesiástico del Obispado de Almería Sede Vacante, 15 de abril de 1845, en Expediente de informes sobre el ex-convento de San Francisco de esta villa, AMCA, leg. 496. 
bastante distantes con perjuicio de la educación de sus hijos y del fomento del país..."

Se pretendía responder así a la petición de la Sección de Instrucción Pública del Gobierno Político de la Provincia para dar cumplimiento a una Real Orden del Ministerio de Gobernación: "Si los edificios conventos que existen en ese pueblo pueden destinarse a establecimientos de instrucción pública o deben ser conservados como monumentos históricos o artísticos, procurando siempre indicar algún objeto de interés general a que puedan dedicarse aquéllos ${ }^{, 20}$. Y para obtener datos fidedignos sobre el grado de conservación del edificio, la corporación ordenará al secretario un detenido reconocimiento que tuvo lugar el 12 de mayo de 1845 bajo la instrucción y asesoramiento de tres peritos alarifes. Llegaron éstos a la conclusión de que la mayor parte de las dependencias se hallaban en un estado ruinoso, tanto que si no se ejecutaba una intervención urgente podrían producirse desgracias. Como consecuencia de esta inspección, el Ayuntamiento emitía dos días después un informe con el que, por encima de cualquier otro objetivo, se pretendía que los espacios del antiguo convento pasasen a titularidad del Municipio, "porque de enajenarlo en venta pública -dado su deplorable estado de conservación- poquísima utilidad ha de resultar a la Hacienda Pública e inmensos perjuicios al procomunal de esta villa". Argumentaban en su favor que, si finalmente se les concediese, velarían para que aquellos espacios fuesen destinados al beneficio de la colectividad, pues de otro modo determinadas necesidades de la población jamás podrían cubrirse "por no haber local ni fondos de que echar mano".Y efectivamente eran abundantes los menesteres sociales que obtendrían inminente respuesta si el Ayuntamiento lograba contar al fin con el edificio:

"[...] en primer lugar se necesita una casa para el maestro de primeras letras con su buena sala para la instrucción de los niños, otra con su sala correspondiente para Estudio de Gramática, otras para Matemáticas y Filosofía, otro local para cárcel, otra para carnicería, para plaza pública, para teatro que ya lo necesita esta población y

\footnotetext{
${ }^{19}$ Borrador, ibidem.

${ }^{20}$ Oficio, íbidem
}

en fin para otros mil objetos de que absolutamente se carece y pudieran destinarse a ello otros dos conventos si los hubiere..."21.

Mientras el Ayuntamiento se afanaba en conseguir unos espacios adecuados para mejorar y generalizar la instrucción publica, la situación de la educación local por aquellos años centrales del XIX en poco difería de la que, con absoluta escasez de medios y locales, se padecía desde principios de esa misma centuria. Por el informante de $\mathrm{Madoz}^{22}$ sabemos que había dos escuelas de niños con 60 alumnos cada una y otras tantas de niñas con 20 discípulas por maestro, es decir 200 niños escolarizados en una entidad de población que a mediados de la década de 1840 superaba ampliamente los 10.000 habitantes. Para 1852 desarrollaban en la localidad funciones educadoras siete maestros de primera y segunda enseñanza ${ }^{23}$.

$\mathrm{Y}$ el edificio del convento, lejos de destinarse exclusivamente a los servicios y utilidades que el Ayuntamiento había pensado en favor y beneficio de la colectividad, siguió arrendándose a unos particulares que le otorgaron los usos más dispares y variopintos, incluidos los docentes. Baste como muestra de esta trayectoria la renovación de inquilinos que tanto el Gobierno de la Provincia como el Municipio autorizaron en época ya muy tardía: el 4 de abril de 1862 la Administración de Fincas del Estado en Almería solicitaba de la institución local que procediese a dar en arriendo la totalidad del edificio a Pedro Tovar Pérez, maestro de primeras letras, quien abonaría 1.500 reales por cada uno de los dos años en que se establecía la duración de aquel contrato $^{24}$. Sin embargo, los cambios que iban a afectar a la propiedad del antiguo establecimiento franciscano no se hallaban muy distantes; el 17 de mayo de 1866, desde Almería se recibe una orden dirigida al alcalde en la que se le notificaba que el antiguo convento de San Francisco había sido una de las fincas exceptuadas de la cesión hecha al Estado por parte del Obispado de Almería, debiendo transferir la posesión del

\footnotetext{
21 “Informe”, 14 de mayo de 1845, ibidem.

${ }^{22}$ Madoz, P. (1845-1850): Op. cit. (pp. 135-136).

${ }^{23}$ Flores González-Grano de Oro, M. (1932). Las Instituciones escolares en Cuevas del Almanzora (Almería) (pp. 1-2). El Censor, 85, de 30 de noviembre de 1932.

${ }^{24}$ Expediente $n^{\circ}$ 14, AMCA, leg. 497.
} 
inmueble al cura párroco como máximo exponente de la jerarquía eclesiástica en la villa ${ }^{25}$. Aquel cambio en la titularidad del edificio tendrá notables repercusiones en las décadas posteriores, sobre todo en el momento de valorar el mayor o menor protagonismo de determinadas instituciones en la promoción y ejecución del colegio de primera y segunda enseñanza Ntra. Sra. del Carmen.

De algunos educadores que ejercieron su notable magisterio en Cuevas poseemos nombres y apellidos, tal fue la impronta que dejaron en la época no sólo entre sus discípulos, sino también, por su inclinación a las artes, en la ya acomodada y elitista sociedad cuevana. Un caso relevante es el de Eugenio Cabezas Villanueva, fraile exclaustrado de amplios y profundos conocimientos en latín, filosofía y matemáticas, quien solicitará permiso para impartir sus clases en el que habían sido convento de San Francisco, edificio que le sirvió igualmente de residencia; dirigió en 1875 El Dómine Rancio, semanario del que se publicaron seis números, y estrenó una zarzuela titulada La Virgen del Mar, a la que puso música el director de El Minero de Almagrera, Antonio $\mathrm{M}^{\mathrm{a}}$ Bernabé Lentisco ${ }^{26}$. Como curiosidad diremos que por entonces, atraído por la presencia de esa numerosa clase adinerada que podía demandar sus específicas enseñanzas, llega a la localidad Luis Dinelli, profesor de gimnasia y esgrima que obtuvo un sonoro éxito entre los hijos de aquella burguesía emergente; fundaría también un periódico titulado Borracheras del tío Cotho ${ }^{27}$.

\section{2.- EL IMPULSO DE UNA BURGUESÍA ORGANIZADA ${ }^{28}$ : CONSTRUCCIÓN Y PRIMEROS AÑOS DEL COLEGIO NUESTRA SEÑORA DEL CARMEN}

\footnotetext{
${ }^{25}$ Expediente $n^{\circ}$ 43, AMCA, leg. 497.

${ }^{26}$ Flores González-Grano de Oro, M. (1932). Op. cit., 1932, p. 9.

${ }^{27}$ Ibidem

${ }^{28}$ A partir de la muerte del absolutista Fernando VII, una burguesía moderada, de inclinación ideológica liberal, se hará con las riendas del poder estatal. Rápidamente pondrán la instrucción educativa a su servicio, concibiendo la enseñanza secundaria como ese conjunto de estudios necesarios para que su clase se perpetuase en ese poder que acababa de conquistar. Es verdad que esta nueva y pujante clase defendía una educación para todos, pero tan sólo en su primer nivel, en las primeras letras; la segunda enseñanza debía reservarse a las clases medias y altas, rectoras ahora y en el futuro de los destinos del país.
}

A finales de la década de 1870 la población había crecido hasta los 21.663 habitantes $^{29}$, pero la situación general de las escuelas de la localidad se apartaba muy poco de ese estado de profunda penuria, de decadencia y de amenazante ruina que se había hecho patente a lo largo de todo el siglo XIX. En mayo de 1878, la prensa provincial - La Crónica Meridional- recogía en sus páginas las lamentables condiciones que ofrecían los establecimientos destinados a la enseñanza de niños que se ubicaban en el antiguo convento, sobre todo en relación a su estado ruinoso, siendo probable que cualquier día pudiese acontecer una tragedia de considerables proporciones. Por esos mismos días el Ayuntamiento había promovido un reconocimiento del edificio que vino a confirmar los peores temores sobre su escasa solidez y seguridad. Y, aunque la amenaza de desplome era más que evidente, no se habían adoptado aún esas medidas de urgencia que garantizasen la integridad de aquellos escolares de primeras letras. De ilustrar esta imagen de galopante decadencia se ocupará el periódico local:

"El arco que da entrada al gran salón de D. Francisco Moya tiene varias grietas, que resultan en el piso alto o sea en el pavimento de la escuela de D. Pedro Tovar. La solana en que se hallan los retretes de la clase de este último profesor está derrumbada y en dichos retretes no se puede penetrar, pues que el suelo está desnivelado y con anchas grietas, y las paredes han perdido su perpendicular, anunciando todo de una manera patente su inmediata ruina ${ }^{\text {"30. }}$.

Días después otro medio de la capital, El Diario de Almería, se hacía eco de ciertos rumores sobre el posible derribo del convento de San Francisco con el fin de dedicar su solar a paseo público. De desmentirlo se ocupará de nuevo El Minero, admitiendo que lo único cierto había sido que el Ayuntamiento había creído oportuno el desalojo de los locales en donde se desarrollaban las lecciones como medida de

\footnotetext{
${ }^{29}$ La cifra puede extraerse de la comparativa que establece con otras capitales de provincia a las que supera en número de habitantes, todo ello según el empadronamiento realizado el 31 de diciembre de 1877. En El Minero de Almagrera, $\mathrm{n}^{\circ}$ 290, 17 de febrero de 1878, p. 2.

30 El Minero de Almagrera, $\mathrm{n}^{\circ}$ 203, 1 de mayo de 1878, pp. 3-4.
} 
precaución ${ }^{31}$. Al mismo tiempo, lo que había constituido una recurrente demanda de las clases más acomodadas se estaba convirtiendo en una reivindicación social que exigía medidas concretas, entre las que sobresalía la rehabilitación del edificio conventual dotándolo de las condiciones y medios necesarios para convertirse en el adecuado establecimiento de enseñanza que precisaba la población. Ahora bien, la intervención exigía de cuantiosas inversiones que -según El Minero- al vecindario de Cuevas no correspondían por no ser el edifico de su propiedad, y porque le sería menos oneroso adquirir otro solar sobre el que levantar un edificio de nueva planta.

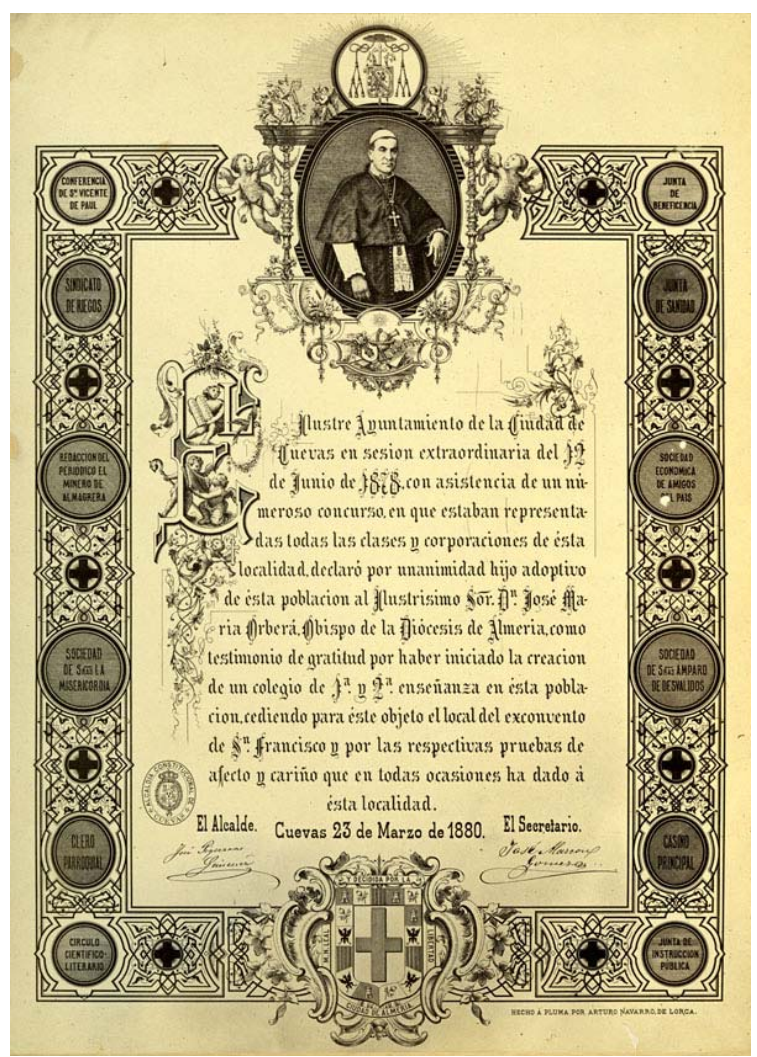

Figura 3.- La contribución del obispo José $\mathrm{M}^{\mathrm{a}}$ Orberá a la expansión de la enseñanza en la localidad fue recompensada por el Ayuntamiento de Cuevas al otorgarle el título de hijo adoptivo el 12 de junio de 1878. (Composición de Arturo Navarro / Fondo Cultural Espín de Lorca).

En realidad el apoyo social hacia la reedificación del convento resultaba cada vez más amplio, hasta el punto de que la Sociedad de Amigos del País, de reciente creación, veía en este proyecto el primer e ineludible paso hacia el

${ }^{31}$ El Minero de Almagrera, $\mathrm{n}^{\circ}$ 206, 25 de mayo de 1878, p. 4. fomento y desarrollo de los intereses públicos. Y este aliento no sólo procedía de Cuevas y sus instituciones, pues la idea de fundar un colegio de $1^{\mathrm{a}}$ y $2^{\mathrm{a}}$ enseñanza, "preparatorio para todas las carreras", cosechaba a través de la prensa los parabienes de Madrid y otras provincias ${ }^{32}$. No habría que olvidar que la riqueza minera de Cuevas atraía a gentes, intereses y capitales desde los más diversos rincones del país, del mismo modo que las relaciones de los cuevanos involucrados en los negocios mineros con otros puntos de España eran estrechas y continuas, lo que explicaría ese interés foráneo por este establecimiento educativo y el ánimo que vertían sobre sus promotores para que, además, elevasen el futuro centro de enseñanza a la categoría de universidad católica.

Ya se dijo más arriba que el antiguo convento franciscano había pasado a titularidad del Obispado de Almería en 1866, de ahí que cualquier proyecto de reutilización de las dependencias monacales debiese contar con la anuencia de la cabeza jerárquica provincial. El 10 de junio de 1878 el obispo José María Orberá visitará la población con el solo objeto de iniciar conversaciones con las autoridades locales sobre la posible creación de un colegio de $1^{\mathrm{a}}$ y $2^{\mathrm{a}}$ enseñanza. Con la misma intención, también se había desplazado hasta allí un representante de los Hermanos de la Doctrina Cristiana, "cuya institución está dando en Francia, Inglaterra, Alemania y demás naciones en que está establecida admirables resultados en la pública enseñanza"33. Para el día 12, el prelado, titular del ruinoso edificio, y el Ayuntamiento habían llegado a un acuerdo sobre la instalación del centro educativo, tras los oportunos arreglos y reformas. La Iglesia cedía "a perpetuidad y gratuitamente" el convento al pueblo con la exclusiva condición de destinarlo a la enseñanza; por su parte, la corporación municipal y los mayores contribuyentes adquirían el compromiso de reedificarlo "con arreglo a los planos que se levanten por la asociación de Hermanos de la Sagrada Familia, a cuyo cargo estará la enseñanza, con la distribución interior de clases, aulas y localidades para la admisión de alumnos internos con sujeción a las prescripciones de su

${ }^{32}$ El Minero de Almagrera, $\mathrm{n}^{\circ}$ 212, 8 de julio de 1878 , p. 3.

33 El Minero de Almagrera, $\mathrm{n}^{\circ}$ 208, 12 de junio de 1878, pp. 3-4. 
regla”34. Desde el mismo momento de su puesta en marcha, aquel centro de instrucción pública se sometería a la dirección conjunta de la Diócesis y de la municipalidad de Cuevas ${ }^{35}$. Su primer y más urgente objetivo se limitaría "a establecer clases completas de $1^{a}$ enseñanza y cátedras de $2^{a}$ enseñanza en las cuales se explicarán en el primer año de su inauguración las asignaturas correspondientes al $1^{\circ}$ y $2^{\circ}$ de Filosofía. En el segundo año de la apertura se cursarán además las del $3^{\circ}$ y así sucesivamente hasta recibir el grado de Bachiller, y prepararse para otras carreras especiales a que el alumno piense dedicarse. El objeto es, después de esto, elevar el establecimiento al alto grado de Universidad católica que sirva de centro de instrucción a donde acuda la juventud..., ${ }^{36}$. El gesto del obispo, instigador de tan loable empresa, fue recompensado mediante su declaración de hijo adoptivo de Cuevas a propuesta del rico minero

34 “Gran acuerdo", en El Minero de Almagrera, $\mathrm{n}^{\circ}$ 209, 22 de junio de 1878, pp. 1-2. Sobre esta orden decía el medio escrito: "La asociación de Hermanos de la Sagrada Familia es un instituto que llena cumplidamente la ardua misión que se ha impuesto. Católica, moral y científica, colocada a la altura de las circunstancias, se dedica con preferencia a la enseñanza, no siendo extraña al estudio de los conocimientos modernos, ni hostil tampoco al verdadero progreso de la civilización, cuyas doctrinas explica y difunde, así como todos los demás ramos del saber humano. Establecida en Francia, en Inglaterra y Alemania, en Europa; en los Estados Unidos, y en varias repúblicas de América del Sur [...]; y en más de 200 años que cuenta de existencia [...] se ha hecho constantemente superior a todos los movimientos, conquistando con su conducta el respeto más profundo y la pública y universal simpatía. [....] En España acaba de establecerse con un colegio-noviciado en Segorbe [...] en donde ha inaugurado la enseñanza bajo tan positivos adelantos que cuenta con más de 700 alumnos, sólo en aquella población".

${ }^{35}$ Tras la aprobación el 9 de septiembre de 1857 de la primera Ley General de Instrucción Publica, conocida como Ley Moyano por el nombre de su promotor, el ministro de Fomento Claudio Moyano Samaniego, se estructuraban todos los niveles de enseñanza desde una moderación política que reconocía los derechos y privilegios que la Iglesia había recuperado o consolidado a raíz del Concordato de 1851. Desde ese instante, aunque el estado ejerza un control exhaustivo sobre todos los niveles educativos sólo financiará la enseñanza superior y profesional, siendo competencia de los municipios la primaria y de la autoridad provincial la secundaria.

${ }^{36}$ Ibidem.
Andrés Soler Herraiz, uno de los principales incitadores del proyecto (figura 3).

El inicio de las obras quedaba supeditado a la conclusión de los planos, y a acelerar el proceso se entregaba la comisión que se había formado con el fin de coordinar las labores de reedificación. Presidida ésta por la máxima autoridad local, ya se encontraba reunida a principios de agosto con el encargo de contratar los materiales precisos para la obra, cuyo inicio se anunciaba para el 9 de septiembre ${ }^{37}$. Sin embargo, a pesar de las críticas vertidas por la prensa local ante el retraso acumulado $^{38}$, el comienzo de los trabajos no será una realidad hasta primeros de febrero de $1879^{39}$. En los meses sucesivos, el único periódico local realizará un seguimiento exhaustivo del proceso de construcción, instigando, si cabe, a la comisión para que incrementase el ritmo de unos trabajos que hasta ese momento habían transcurrido con notable lentitud. Hay preocupación porque, dado el retraso, el curso académico no podrá inaugurarse, como sería deseable, en septiembre de 1879 , y esto se pone de manifiesto en las propias alternativas que plantea el sector más acaudalado -y también más interesado- de la población:
“¿No sería posible el que el instituto de enseñanza libre se abriera provisionalmente en otro local y que se evitara de este modo el perjuicio que ocasiona con la clausura o la negación de todo el curso académico? Puede haber dificultad en el magisterio pero, ni aun ofrece esto mucha, cuando nos consta que no falta personal inteligente y que hay algunos que revestidos de los títulos profesionales en ciencias y en letras, prevenidos en la ley vigente de instrucción pública, deseosos de prestar servicios útiles, se ofrecen voluntaria $y$ gratuitamente a explicar las asignaturas diarias y alternas que para cada año exige el plan general de instrucción pública "40.

\footnotetext{
37 El Minero de Almagrera, $\mathrm{n}^{\circ}$ 216, 8 de agosto de 1878, p. 3.

${ }^{38}$ El Minero de Almagrera, $\mathrm{n}^{\circ}$ 229, 17 de noviembre de 1878, p. 4.

${ }^{39}$ El Minero de Almagrera, $\mathrm{n}^{\mathrm{0}}$ 238, 5 de febrero de 1879, p. 4.

${ }^{40}$ El Minero de Almagrera, $\mathrm{n}^{\circ}$ 267, 4 de septiembre de 1879 , p. 3.
} 
Pero los tiempos que se avecinaban no serían precisamente favorables a la conclusión del colegio. El 14 de octubre de 1879 el río Almanzora y su principal afluente en la cuenca baja, la rambla de Muleria, protagonizarán una catástrofe de proporciones desconocidas para los habitantes de Cuevas y su término. Una descomunal riada produjo decenas de víctimas, pérdidas muy cuantiosas en la agricultura y la minería, arrasadas su vega y las explotaciones de Herrerías por el ímpetu de las aguas, y causó profunda desolación en una comunidad que durante el último lustro no había atravesado por su mejor momento económico. Constituyó el triste colofón de una etapa aciaga que se pretendía superar mediante la implicación de la sociedad civil en un conjunto de proyectos revitalizadores, como la traída de las aguas potables, la promoción de vías de comunicación o el mismo fomento de la instrucción pública, entre otras iniciativas auspiciadas por el Municipio, la Sociedad de Amigos del País y las distintas comisiones gestoras.

Sea como fuere, aquella calamidad natural tuvo en la paralización de las obras que se realizaban en el convento una de sus primeras y más destacables consecuencias. Transcurridos casi siete meses del aluvión, algunas voces ${ }^{41}$ volvían a ocuparse de la mermada situación que presentaba la enseñanza pública en una localidad en la que, habiéndose sobrepasado ya los 21.000 habitantes, existían tan sólo tres escuelas de primeras letras; y mostrando su más absoluta indignación, traían de nuevo a colación las múltiples carencias materiales y el deplorable estado de conservación de los locales:

"Escuela hay cuyo local es de 20 metros cuadrados de superficie que apenas tiene la suficiente capacidad para 40 alumnos, en el cual pasa de 250 el número de los que concurren, expuestos a la asfixia y a las enfermedades, $y$ en la absoluta imposibilidad de que aprendan y deseen concurrir a aquel establecimiento de instrucción que es lugar infecto de incomodidad y de martirio" 42

No se trataba nada más que de contundentes argumentos que debían sustentar una única

\footnotetext{
41 “Instrucción pública”, en El Minero de Almagrera, $n^{\circ} 301,8$ de mayo de 1880, pp. 1-2.

42 “Las escuelas de Cuevas", en El Minero de Almagrera, $\mathrm{n}^{\circ}$ 302, 19 de mayo de 1880 , p. 3 .
}

reivindicación: la definitiva conclusión de las obras del futuro colegio de $1^{\mathrm{a}}$ y $2^{\mathrm{a}}$ enseñanza.

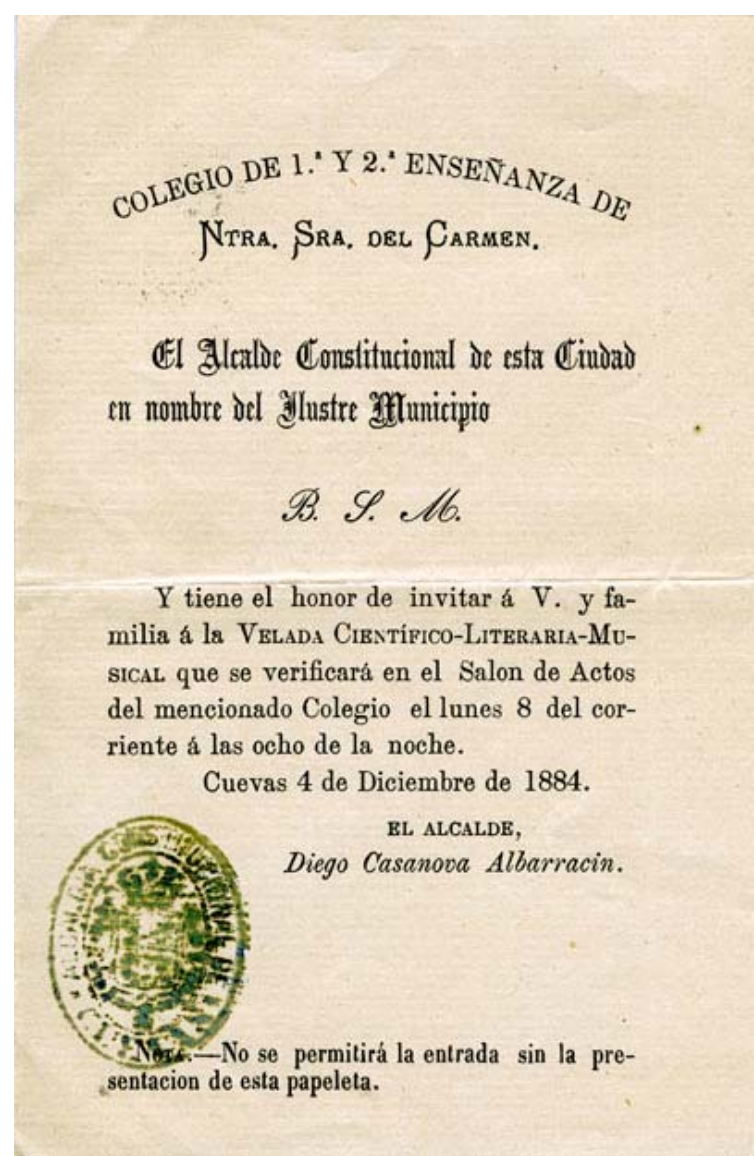

Figura 4.- Invitación cursada por el alcalde de Cuevas, institución del que dependía administrativamente el Colegio Nuestra Señora del Carmen, para asistir a una de aquellas veladas culturales que tenían lugar en sus dependencias educativas. (Col. Enrique F. Bolea).

Por fin, el 19 de octubre de 1881 se celebran los fastos de inauguración del colegio Ntra. Sra. del Carmen, incorporado desde este preciso momento al Instituto Provincial de Almería. El acto estuvo presidido por Mariano Flores Gómez, teniente de alcalde, el párroco de la población y el primer director del establecimiento, Anselmo Jordán y Olivier, acompañados en lugar de privilegio por miembros del gobierno municipal, de la Junta Local de Instrucción Pública y de la Comisión organizadora del Colegio ${ }^{43}$. Al final, el Ayuntamiento no había llegado a un acuerdo con

${ }^{43}$ La crónica de la inauguración, con los contenidos de los discursos y los particulares de la jornada, quedan referenciados en "Fausto acontecimiento. Inauguración del Colegio de Ntra. Sra, del Carmen”, en El Minero de Almagrera, $\mathrm{n}^{\circ}$ 371, 21 de octubre de 1881, pp. 1-2. 


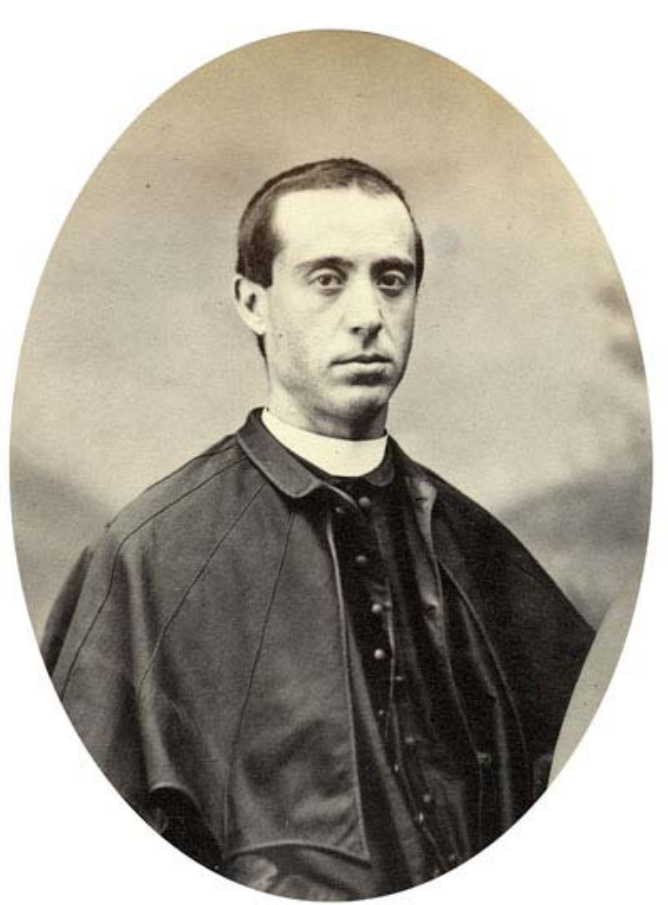

Figura 5.- El presbítero Miguel Molina Valero, afamado poeta y dramaturgo local, fue uno de los seleccionados para integrar el primer claustro de profesores del Nuestra Señora del Carmen. (Foto de José Rodrigo / Archivo Histórico Municipal de Lorca).

los religiosos de la Sagrada Familia, en los que primeramente se había pensado -como tuvimos ocasión de ver- para ocuparse del destino de la institución. En su lugar, los responsables municipales optaron por la contratación de un claustro de profesores, integrado por laicos y religiosos, a los que se les exigió amplia formación y experiencia. De este modo, de la dirección espiritual del nuevo colegio se ocuparía el presbítero local Diego Fernández Fernández, quien además explicaría las cátedras de Latín y Religión y Moral ${ }^{44}$. La dirección pedagógica y administrativa recaería sobre el ya citado Anselmo Jordán, adornado de un profuso currículo, pues era doctor en Filosofía y Letras, licenciado en Derecho Civil y Canónico, y bachiller en Sagrada Teología. Otros integrantes del equipo docente fueron el afamado vate y dramaturgo cuevano, presbítero de ocupación, Miguel Molina Valero ${ }^{45}$ (figura 5); el licenciado

\footnotetext{
44 Flores González-Grano de Oro, M. (1932). Op. cit. (p. 10).

${ }^{45}$ Véase Fernández Bolea, E. (1999). Colaboraciones literarias de Miguel Molina Valero en El Minero de Almagrera (pp. 206-213). Axarquía, 4; y Fernández Bolea, E. (2006). Molina Valero, Miguel (p. 259), en J. P. Díaz López (coor.), Diccionario biográfico de
}

Antonio Bueno, director del establecimiento en los años finales de la década de 1880, quien después ocuparía una cátedra en el Instituto Provincial de Almería; o el que durante un tiempo cumpliría con el cargo de vice-director, Juan Benllot y Vivó, que, habiéndose consagrado con posterioridad a la Iglesia, alcanzó el Principado de Andorra y el Obispado de la Seo de Urgel, ocupando al final de sus días el Arzobispado de Burgos ${ }^{46}$

Desde su primer curso académico, la dirección, a instancias del Municipio y de las Juntas de Instrucción y Colegio, convocará tres plazas gratuitas en la modalidad de externos entre los vástagos de aquellas familias cuya situación económica "no alcance al sostenimiento y demás atenciones que lleva consigo una carrera" ${ }^{\text {47 }}$. Los aspirantes, acreditada tal limitación mediante los documentos requeridos, debían superar un examen consistente en dos preguntas de Historia Sagrada, cuatro de Gramática Castellana, tres de Aritmética, doce de Doctrina Cristiana y ejercicios de lectura y escritura.

Tantos años anhelando un centro educativo como el que acababa de abrir sus puertas provocaron en los cuevanos una enorme expectación. Con bastante frecuencia, a las lecciones asistían en calidad de oyentes representantes de las clases acomodadas, miembros en algún caso de la Junta de Instrucción, que asumieron al instante la inspección de todo lo que allí sucedía ${ }^{48}$. Sin embargo, de sus visitas sólo se desprendían elogios hacia el buen funcionamiento de una institución donde catedráticos y alumnos concurrían con extrema puntualidad, donde unos y otros se aplicaban con desmedido interés a sus distintas funciones, donde las clases se desarrollaban con gran aprovechamiento debido a la claridad y sencillez de una explicaciones que favorecían la fácil comprensión de los alumnos.

Almería. Almería: Instituto de Estudios Almerienses y Cajamar.

${ }^{46}$ Discurso inaugural del Colegio de Nuestra Señora del Carmen de Cuevas pronunciado el 16 de octubre de 1893 por el M. R. P. Fr. Manuel Bada, de la orden de Predicadores. Cuevas: Est. Tip. de Serafín Campoy, 1893, p. 11.

47 Anuncio del Colegio de Segunda Enseñanza de Ntra. Sra. del Carmen inserto en El Minero de Almagrera, $\mathrm{n}^{\circ} 369,4$ de octubre de 1881, p. 4.

${ }^{48}$ El Minero de Almagrera, no 375,18 de noviembre de 1881, p. 2. 
Como vemos, alabanzas por doquier que culminaban con el buen hacer de la dirección del establecimiento, preocupada por el progreso de los discípulos: “[...] el Sr. Jordán reúne los domingos a todos los matriculados; los examina de lo estudiado en la anterior semana; premia a los más aventajados y los prepara para los exámenes y conferencias públicas que se propone celebrar periódicamente...”.

Por aquellas aulas pasaron los hijos de las familias más adineradas de Cuevas y toda la comarca, así como otros que, procedentes de la misma capital y provincias limítrofes, se vieron atraídos por el prestigio que aquella institución educativa había alcanzado. Esta primera etapa en la trayectoria del Colegio se cerraría con el curso 1891/92, ocupando las funciones de director el presbítero Diego Fernández ${ }^{49}$.

\section{3.- CONSOLIDACIÓN Y PRESTIGIO BAJO LA TUTELA DE LOS DOMINICOS.}

En efecto, en junio de 1892 el establecimiento cerró sus puertas con el objeto de afrontar importantes trabajos de reforma y ampliación. Pero a esta intervención material se iba a sumar la intención convencida de renovar el claustro de profesores, pues se respondía así a un anhelo arrastrado desde los mismos orígenes del centro educativo. No hay que olvidar que tanto el obispo Orberá, en los inicios de la institución, como su sucesor Santos de Zárate habían hecho denodados esfuerzos para que aquel colegio estuviese regido por una orden religiosa. Y aunque hasta aquel momento todos los intentos habían resultado estériles, desde principios de la década de 1890 se habían establecido conversaciones con los Dominicos a través de alguno de los frailes de esta orden que se habían desplazado hasta Cuevas para la predicación cuaresmal; las autoridades municipales y el Obispado aprovecharon la ocasión para hacer saber al padre provincial su interés, ofreciéndole el edificio y el apoyo necesario para que se decidieran a tomar las riendas del centro educativo. Finalmente, el padre provincial accedió a las demandas de los cuevanos y presentó su pliego de condiciones. La profunda crisis por la que atravesaban los distritos mineros, con la consiguiente paralización de la mayoría de las explotaciones, hizo planear la duda sobre la capacidad de la población para afrontar las exigencias que se preveían indispensables en este proceso de instalación de la congregación dominica en el antiguo colegio.

$\mathrm{Y}$ es que los gastos iban a ser notables y la disponibilidad más bien reducida:

"Correspondencia postal y telegráfica con las autoridades eclesiástica y académica de la provincia y con los venerables PP. Dominicos; viajes a la capital de la provincia; obras de reparación y construcción de celdas y dormitorios en el edificio y en la iglesia al mismo aneja; adquisición de terrenos $y$ edificios, los unos para ensanches del establecimiento y para nuevas construcciones los otros; $y$, para acabar, esas mil y mil otras cosas..." "50.

Y fue un sector capitalista de la población, encabezado por varias señoras dadivosas, asiduas cultivadoras de la filantropía, el que logró al final vencer las dificultades económicas aportando de su peculio los fondos precisos. Papel relevante en este proceso fue el de María de la O Flores Fernández $^{51}$, precursora indiscutible de esta nueva etapa, quien llegará a donar unas 13.000 pesetas de la época, además de la cesión de un edificio $^{52}$. Porque la obras que se acometieron entre finales de 1892 y 1893 supusieron una rehabilitación general del antiguo convento, a lo que se añadió la adquisición de varias casas situadas enfrente del inmueble con el fin de levantar un edificio anexo de nueva planta en el que ubicar aulas, local para enseñanza primaria y dormitorios para el alumnado interno ${ }^{53}$. Al desprendimiento de María de la O Flores, y como consecuencia de su capacidad para atraer dinero y voluntades hacia aquel proyecto, se unió el de

\footnotetext{
${ }^{50}$ Discurso inaugural del Colegio de Nuestra Señora del Carmen..., 1893, p. 11.

${ }^{51}$ Véase Martínez Navarro, P. E. (2007). Semblanzas, perfiles y notas biográficas de cuevanos y cuevanas ilustres. Cuevas del Almanzora: Ayuntamiento de Cuevas y Arráez Editores, [2ª Ed.], pp. 107-111.

52 Discurso inaugural del Colegio de Nuestra Señora del Carmen de Cuevas...,1893, p. 12.

53 Flores González-Grano de Oro, M. (1932). Op. cit. (p. 11).
}

\footnotetext{
${ }^{49}$ Flores González-Grano de Oro, M. (1931). Op. cit. (p. 10).
} 
otras señoras de la enriquecida burguesía local (figura 6), como las hermanas Magdalena y Catalina Soler Márquez ${ }^{54}$ o Dolores de Miguel, con contribuciones de $7.500,1.250$ y 2.500 pesetas respectivamente; las generosas 7.500 pesetas que allegó el conde de Miguel, las 1.000 del banquero Juan Antonio Núñez, o las más modestas cantidades aportadas por los médicos Andrés

Pérez López y Antonio Pérez Doménech, con 500 y 250 pesetas respectivamente ${ }^{55}$. Ahora bien, todos estos benefactores quisieron expresar mediante documento notarial que "la parte construida a sus expensas quedaba sujeta a las mismas restricciones en cuanto a la enseñanza y educación que las impuestas por el Obispo Sr. Orberá -es decir, que el destino de aquellas instalaciones fuese siempre la enseñanza-, disponiendo, en el caso de que no se cumplieran aquéllas, que el edificio pasase a poder de sus legítimos herederos" $" 56$.

Por fin, a mediados de julio de 1893, una vez comprobado que se cumplía con las estipulaciones fijadas en su pliego de condiciones, los Dominicos adquirían el compromiso de dirigir el Ntra. Sra. del Carmen desde el siguiente curso académico ${ }^{57}$. El 15 de septiembre llegarán a la población fray Manuel Bada y fray Filiberto Díaz, delegación que se ocupará de los trámites previos a la apertura del colegio, así como de la inspección de los espacios reformados y los que aún se hallaban en construcción. Hasta el 28 de ese mismo mes se prolongaría el plazo de matriculación en todas las asignaturas que integraban los planes de primera

\footnotetext{
${ }^{54}$ Cuñadas de María de la O Flores (figura 8), procedían de la que posiblemente era la familia más acaudalada de la localidad por aquellos años finales del siglo XIX. Eran hijas del rico banquero y fundidor Manuel Soler Gómez, quien, a su fallecimiento en 1891, había repartido entre sus tres hijos vivos -Antonio, Magdalena y Catalina- y su nuera María de la O -viuda de Miguel Soler Márquez- una inmensa fortuna. Podríamos decir, pues, que más de la mitad del capital donado para las obras de restauración y ampliación del Colegio procedían de la herencia dejada por el opulento Manuel Soler.

${ }^{55}$ El detalle de las cantidades donadas proviene de Discurso inaugural del Colegio de Nuestra Señora del Carmen..., 1893, p. 12.

${ }^{56}$ Flores González-Grano de Oro, M. (1932). Op. cit. (p. 11).

${ }^{57}$ En El Minero de Almagrera, n ${ }^{\circ}$ 935-936, 22 de julio de 1893, p. 7.
}

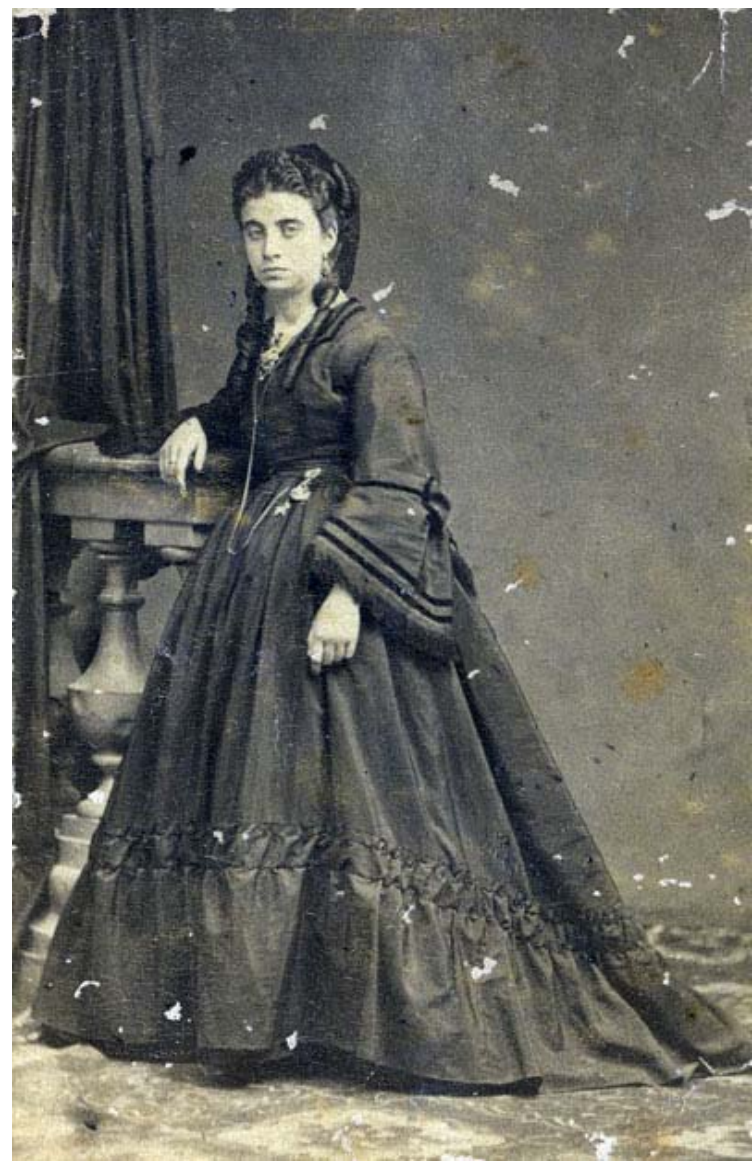

Figura 6.- Dama de la enriquecida burguesía cuevana, Magdalena Soler Márquez participó activamente en los trámites previos a la venida de los frailes dominicos y contribuyó al arreglo y ampliación del colegio. Hacia 1875. (Foto de José Rodrigo / Col. Enrique F. Bolea).

y segunda enseñanza, oferta que se veía ampliamente complementada con otras materias no obligatorias como música vocal e instrumental, dibujo, gimnasia, etc. En el prospecto editado para dar publicidad a su propuesta educativa, los dominicos especificaban la admisión de alumnos en régimen de internado, medio-internos y externos, y la garantía de enseñanza gratuita a "los verdaderamente pobres" $" 58$.

Y llegó el día de la reinauguración del colegio, ese día 16 de octubre en que lo más granado de la sociedad cuevana, las autoridades civiles y eclesiásticas, inundaron el templo de San Francisco, anexo al edificio conventual, para ser parte del boato que adornó una jornada que supuso la culminación de antiguas y reiteradas

${ }^{58}$ En El Minero de Almagrera, no 941-942, 16 de septiembre de 1893, p. 7. 
aspiraciones. Aunque la extensión sea considerable y su expresión en exceso afectada, merece la pena ahora -por lo que posee de rutilante fresco de una época extinguida, de un estado ya trasnochado de relaciones jerárquicas y sociales, de aquellas galas y vanidades otrora exhibidas en los grandes actos- reproducir con exactitud literal lo que nos dice el cronista del periódico local sobre los asistentes a aquellos fastos de inauguración y el rígido protocolo que allí imperó:

“[...] en el presbiterio, detrás de la mesa presidencial, de rico damasco vestida, y en el lugar preferente de ella, cual así a su alta jerarquía es debido, el sabio y virtuoso prelado de la Diócesis -Santos de Zárate-, con sus moradas vestiduras símbolos de aflicción y el áureo pectoral, remembranza de antiguas costumbres; a la derecha del prelado, la autoridad local, genuina representación de la ciudad de Cuevas, y a su izquierda el digno e ilustrado rector del Colegio con su hábito blanco como la pureza de las sagradas enseñanzas y su manteo oscuro en señal de humildad y penitencia; más allá, a la derecha de la autoridad civil y por supuesto en el mismo presbiterio, para este acto convertido en estrado, el venerable cura párroco de esta iglesia, con el modesto traje talar propio de su estado y enfrente de dicha autoridad, a la izquierda del rector del establecimiento, la autoridad judicial, representación de la santa virtud que tiene por objeto el derecho de cada uno y por fin el dar a cada cual lo que es suyo; abajo, junto a las marmóreas gradas que dan acceso al presbiterio, de tupida alfombra cubierta, la corporación municipal y demás invitados a la académica festividad, cruzando el pecho de los unos honrosas bandas, ostentando los otros preciadas condecoraciones junto a cuyas galas parece como que resaltan con doble brillo los humildes cendales de los sacerdotes presentes también al acto; a los lados, y detrás, $y$ en las naves laterales, $y$ en el coro y por todas partes, un público nutrido, selecto, y por extremo satisfecho, entre el cual asoman de vez en cuando los semblantes juveniles de los bulliciosos escolares, de suyo tan alegres y en aquellos momentos como por la trascendencia del acto hipnotizados; en el centro de la nave principal del templo y ocupando la mayor parte de ella, y por detrás también de los sillones y escaños destinados a los hombres, la dulce compañera de éste en sus días de aflicción y en sus horas de placer, las señoras más distinguidas de la sociedad cuevana, jóvenes las unas, madres las otras de aquellos a la vez absortos y alegres escolares, compartiendo así con su presencia en aquel público y solemne acto la satisfacción que embarga todos los pechos por la razón de lo que éste significa y lleva tras de sí, como indeclinable consecuencia, y quizás, como madres, más aun que ellos conmovidas por la indudable importancia de la festividad, principio para los hijos de sus entrañas de una nueva vida, y en aquella ocasión, orgullosas además como mujeres, de que a una de su sexo, a una de ellas -M ${ }^{\mathrm{a}}$ de la O Flores Fernández-, a una amiga de todas se deba la feliz iniciativa de la importante obra cuya inauguración se celebra" $"$ ".

La interpretación de selectas composiciones musicales de los mejores maestros por parte de la banda municipal, los discursos del reverendo padre Bada, primer rector de Ntra. Sra. del Carmen, y del obispo, y un abundante $\mathrm{y}$ espléndido "lunch" servido en su espacioso salón de actos completaron la programación de aquella jornada de marcada significación histórica para Cuevas.

Tan exhaustivo era el seguimiento que hacía la buena sociedad cuevana de la actividad académica del Colegio que la celebración de los exámenes preparatorios en junio de 1894 suscitó enorme expectación e interés, hasta el extremo de ser objeto de atención de una prensa que no dudaría en orear los óptimos resultados que el magisterio de los dominicos había conseguido de sus discípulos ${ }^{60}$. Y será precisamente en ese momento cuando se anuncie la pronta conclusión del edificio de nueva planta en donde se ubicarán espaciosos dormitorios con capacidad para unos cien alumnos internos, destinándose su planta

\footnotetext{
59 “La inauguración del Colegio el día 16 de octubre”, en El Minero de Almagrera, $\mathrm{n}^{\circ}$ 945, 16 de octubre de 1893, pp. 2-4.

60 “Colegio de Ntra. Sra. del Carmen”, en El Minero de Almagrera, $\mathrm{n}^{\circ}$ 978, 24 de junio de 1894, p. 3.
} 
baja a aulas para el desarrollo de las clases de segunda enseñanza y escuela de primera enseñanza (figura 9).

De este modo, el antiguo edificio conventual podría dedicarse con exclusividad a habitaciones para los padres profesores, gabinetes de física y química, museo de historia natural, salas de música y dibujo y otros espacios comunes. La inminente mejora de las instalaciones y los óptimos resultados académicos obtenidos durante ese primer curso 1893/1894 sirvieron de revulsivo para que el número de solicitudes aumentase considerablemente, de ahí que ya en junio de 1894 fuesen unos cien los demandantes de plaza en régimen de internado para el curso venidero.

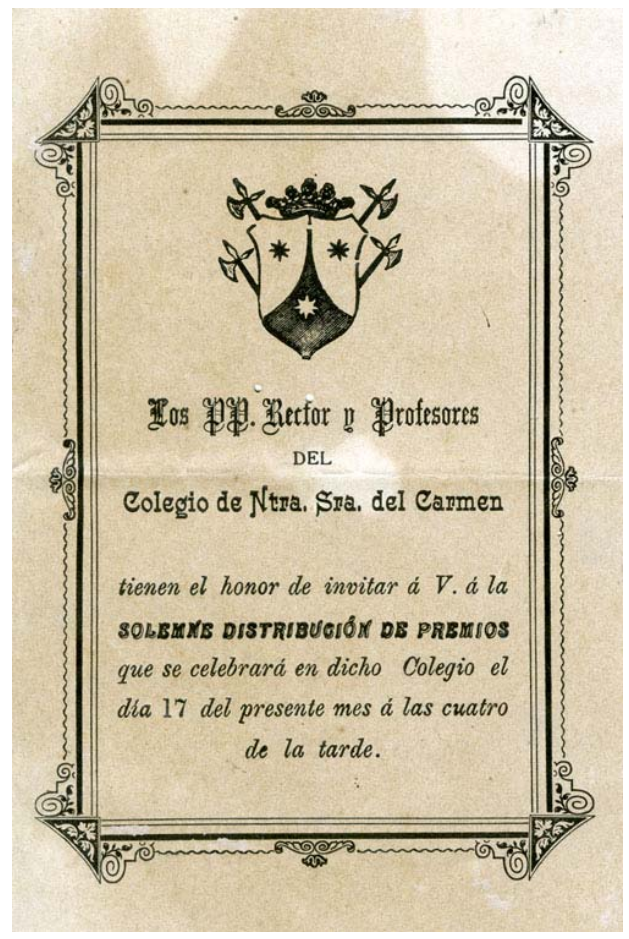

Figura 7.- Los Dominicos invitan a la distribución anual de premios académicos entre sus alumnos. Hacia 1895. (Col. Enrique F. Bolea)

El Semanario Popular de Almería se sumaba a esa coral de incondicionales aduladores y lo calificaba de "uno de los mejores, o el mejor de la provincia, no sólo por estar a cargo de una Corporación tan acreditada en la enseñanza, sino también por las condiciones inmejorables del edificio en que está instalado" ${ }^{6}$. Y por

\footnotetext{
${ }^{61}$ La noticia la recoge, con el título "El Colegio de Cuevas”, El Minero de Almagrera de este periódico almeriense en su $n^{\circ} 989-990$, de 27 de septiembre de 1894, pp. 2-3.
}

aquellos días finales de septiembre de 1894, justo antes de iniciarse el nuevo período académico, anunciaba "a las numerosas familias interesadas

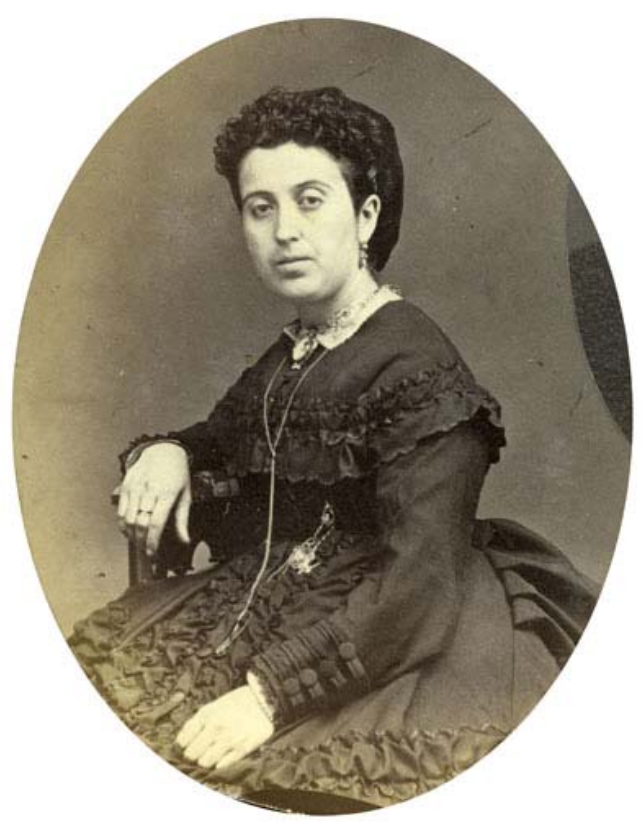

Figura 8.- La desprendida María de la O Flores Fdez., miembro de una de esas opulentas familias de la burguesía local, fue la máxima impulsora de este proyecto educativo a través de la donación de importantes cantidades de dinero. Hacia 1875. (Foto José Rodrigo / Arch. Histórico Municipal de Lorca).

en la sólida y cristiana educación de sus hijos” que los trabajos de ampliación y embellecimiento del colegio se hallaban completamente concluidos, pasando a enumerar las flamantes dependencias con cierta admiración: “[...] espaciosos dormitorios, elegantes lavabos de mármol, enfermería magnífica, salones de estudio muy capaces, museos y gabinetes dotados de abundante material científico, dos frontones para juego de pelota, etc.". Nos enteramos a través de este mismo medio escrito de que el precio de la matrícula por trimestre para los alumnos internos ascendía a 250 pesetas, reducida cantidad -opina el periódico- si se tiene en cuenta la calidad de la enseñanza, el esmerado trato, la comida variada y abundante, el lavado y planchado de la ropa, la asistencia médica y demás servicios ${ }^{62}$, a lo que debía añadirse, como

\footnotetext{
${ }^{62}$ Nos hemos enterado después, en el momento de transcribir el Reglamento que constituye el Apéndice documental que acompaña a este artículo, de que el periodista almeriense exagera a la hora de considerar los servicios incluidos en el precio de matrícula, ya que ni el lavado y planchado de la ropa ni la asistencia
} 


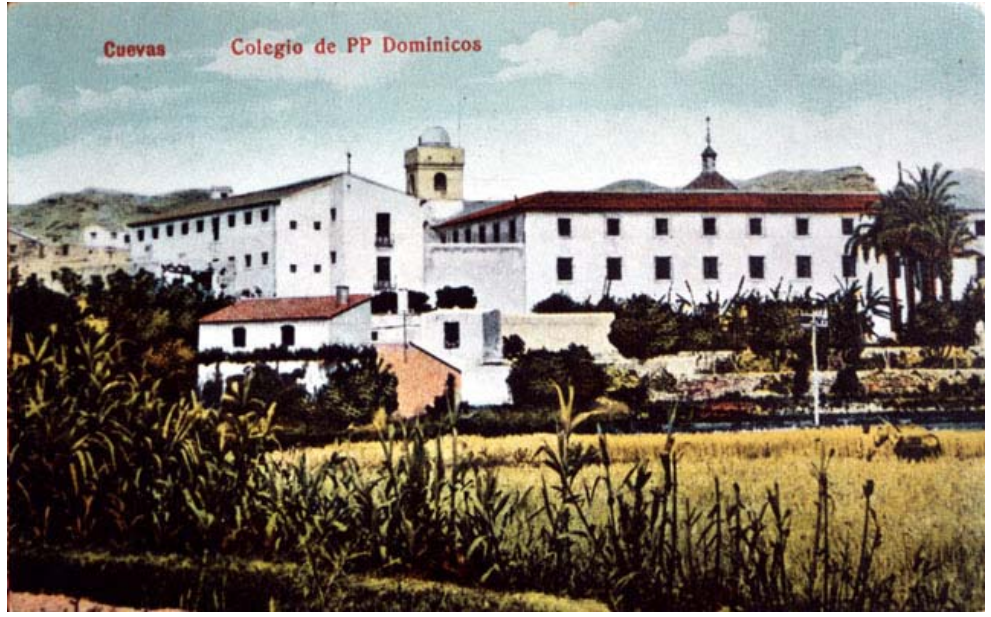

Figura 9.- Vista panorámica del colegio, apreciándose a la derecha del campanario el antiguo edificio conventual y a la izquierda del mismo el edificio de nueva planta que supuso una notable ampliación de las instalaciones educativas. Postal coloreada datada hacia 1910. (Foto de Federico de Blain Becerra / Col. Enrique F. Bolea). aspecto esencial, las garantías que los padres dominicos ofrecían a la formación de sus discípulos, tal y como se había puesto de manifiesto durante el desarrollo de los exámenes finales de junio en el Instituto de la capital, donde los alumnos del Ntra. Sra. del Carmen obtuvieron algunos de los mejores resultados de la provincia. Consideraba igualmente la prensa capitalina que la notable ampliación que había recibido el centro docente, con la apertura de un nuevo edifico anexo, le otorgaba "un ensanche, comodidad y condiciones higiénicas tan excelentes que difícilmente las reunirá otro de igual índole”; y apostillaba después: “[...] bien puede asegurarse que el moderno Colegio de Ntra. Sra. del Carmen de Cuevas se ha colocado a grande altura y nada tiene que envidiar a los más acreditados de España”.

Tampoco reparaba en alabanzas el corresponsal de La Restauración cuando, justo al año siguiente y coincidiendo con el inicio del curso 1895/1896, se detenía de nuevo en la descripción de las magníficas instalaciones (figura 9), en sus "corredores espaciosos, vastas salas de estudio, gabinetes y museos con el correspondiente material científico, aulas muy capaces y ventiladas, departamentos magníficos para dormitorios, roperos y enfermería, en los cuales hay hasta unas cien camarillas; recreos muy extensos, con juegos de pelota, y huerta con condiciones difíciles de hallar aun en los

médica estaban cubiertos. Véase Reglamento del Colegio de Ntra. Sra. del Carmen bajo la dirección de los PP. de la Orden de Predicadores (Dominicos), Cuevas (Almería). colegios más nombrados de las capitales"63.Y no se olvidaba de encomiar la labor docente de los frailes $y$ los resultados que de ella se desprendían, auténtico fundamento del prestigio que estaba alcanzando la institución: “Los resultados hasta el presente conseguidos han merecido [...] éxitos, aplausos comprobados en la piedra de toque de las oposiciones al premio en el Instituto -se refiere al Provincial de Almería-, en las cuales los alumnos de Cuevas alcanzaron los más brillantes triunfos”.

Sin embargo, este incremento de fama y prestigio no había relajado a los responsables de la institución y a sus benefactores en esa continua inclinación hacia la mejora de las instalaciones. $\mathrm{Su}$ principal impulsora, María de la O Flores (figura 8), había conseguido del Ayuntamiento el firme compromiso de dotar al Colegio de agua corriente $^{64}$, pero como en otras ocasiones el tiempo transcurría y a la promesa no se le daba el debido cumplimiento. Ante esta falta de respuesta, aquella señora optaría, después de solicitar los pertinentes permisos municipales, por conducir a su costa las aguas potables hasta el establecimiento, "en recompensa de los numerosos beneficios que dicha comunidad viene reportando a esta ciudad tanto en el orden moral cuanto en el material"65. Los trabajos, que ya se

63 Reproducido con el título de "Colegio de Nuestra Señora del Carmen en Cuevas” por El Minero de Almagrera, $\mathrm{n}^{\circ}$ 1.037, 19 de septiembre de 1897.

64 Sobre este particular véase Fernández Bolea, E. (2006). Agua y vida en Cuevas del Almanzora. Una historia de luchas y anhelos. (Siglos XVI - XXI). Cuevas del Almanzora: Arráez Editores, pp. 288-289.

${ }^{65}$ Actas capitulares, 7 de agosto de 1895, AMCA, lib. 125. 
hallaban iniciados a mediados de septiembre de 1895, progresaban a buen ritmo ${ }^{66}$, y en los comienzos de octubre se había completado la conducción hasta el edificio y se procedía entonces a la distribución del servicio por sus distintas dependencias ${ }^{67}$. Otras modernidades exigidas por el correr de los tiempos, como la luz eléctrica y el teléfono ${ }^{68}$, tendrían en aquel establecimiento docente el primer espacio de aplicación en la localidad.

Ahora bien, Ntra. Sra. del Carmen no destacaría sólo por las mejoras e innovaciones materiales, ya que desde su fundación en 1881 se había convertido en un centro de saber y cultura de primer orden en el panorama provincial. No obstante, desde la llegada de los dominicos ese papel se había acrecentado notablemente gracias a la trascendencia que la orden concedía a espacios de ciencia y conocimiento como los distintos gabinetes, el observatorio astronómico, la biblioteca y el museo. A ello contribuirán las inclinaciones científicas y profusas inquietudes intelectuales de algunos de los miembros de la congregación que, como el sabio y entusiasta padre Paulino Quirós, tanto se destacaron en el fomento de la arqueología y tanto ayudaron al incremento de las colecciones del colegio. Hasta los anaqueles y vitrinas de su museo arribaron piezas desenterradas en Villaricos, como "un importante trozo de una estatua de mármol, coronación al parecer de un antiguo monumento que adornaba alguna plaza de la antigua Urci"69, o un magnífico capitel corintio de mármol blanco, legadas ambas antigüedades por Antonio Abellán Casanova, II Marqués de Almanzora ${ }^{70}$. El mismo padre Quirós depositará allí muchos de los restos extraídos de las prospecciones arqueológicas que promovió y dirigió en Villaricos ${ }^{71}$, costeadas por los propios

\footnotetext{
${ }^{66}$ En El Minero de Almagrera, n ${ }^{\circ} 1.037,19$ de septiembre de 1895, p. 4.

${ }^{67}$ En El Minero de Almagrera, $\mathrm{n}^{\circ} 1.040,9$ de octubre de 1895, p. 4.

${ }^{68}$ Consúltese el sabroso capítulo que dedica Molina Sánchez, A. (1990) a "El primer teléfono”, en El libro de Cuevas del Almanzora hace un siglo. Almería: Ayuntamiento de Cuevas del Almanzora, pp. 250-253.

${ }^{69}$ En El Minero de Almagrera, $n^{\circ} 1.113,16$ de abril de 1897, p. 4.

${ }^{70}$ En El Minero de Almagrera, ${ }^{\circ}$ 1.117, 16 de mayo de 1897, p. 4.

${ }^{71}$ En la apertura del curso académico 1897/98, fray Paulino Quirós leyó el discurso inaugural; con él pre-
}

dominicos. Un parecido y constante flujo de donaciones aumentó de modo considerable los fondos bibliográficos del colegio, pues fueron numerosas las cesiones recibidas tanto de particulares como de otros establecimientos de la misma orden ${ }^{72}$, conformándose al final una rica y variada biblioteca que sirvió de apoyo para la formación de las distintas promociones que frecuentaron aquellas aulas. El cronista Miguel Flores denunciará que, cuando la orden de Predicadores de Santo Domingo de Guzmán abandone el establecimiento, se llevará consigo "preciosos e interesantes objetos del museo arqueológico del Colegio donados por particulares, gran número de monedas antiguas, entre las que se contaban algunas piezas raras $y$ valiosas, y libros que debieron respetar porque pertenecían a la casa"73.

El colegio seguiría consolidando su prestigio en los años sucesivos, lo que sirvió para que padres de toda la provincia confiaran la educación de sus hijos a estos frailes. Precisamente en el aumento del número de alumnos se ponía de manifiesto la alta consideración que se tenía de aquel centro docente, donde en el curso 1897/1898 y sólo en régimen de internado habían formalizado su matrícula casi cien jóvenes ${ }^{74}$ (figura 10) La integración de esta institución educativa en la vida social y cultural de la población fue permanente desde sus inicios, hasta el punto de

tendió erradicar un afianzado error, convertido casi en inapelable creencia entre historiadores y arqueólogos, sobre la ubicación de la antigua y mítica ciudad de Urci, a la que a veces se le había dado una supuesta localización en Villaricos. Quirós será el primero que, basándose en sus estudios y observaciones sobre el terreno, desmienta la anterior creencia y sitúe en la aldea costera la ciudad púnico-fenicia conocida con el nombre de Barea o Baria. "Colegio de Nuestra Señora del Carmen”, en El Minero de Almagrera, $\mathrm{n}^{\circ}$ 1.136, 12 de octubre de 1897, pp. 2-3. Véase también Grima Cervantes, J. \& Fernández Bolea, E. (2004). Baria: una ciudad de la Antigüedad clave para entender nuestro pasado y trascendental como pilar del patrimonio histórico y arqueológico de la Axarquía almeriense. Axarquía, 9, p. 162.

72 Véase El Minero de Almagrera, números 1.117, 1.119 y 1.125 , entre mayo y julio de 1897.

${ }^{73}$ Flores González-Grano de Oro, M. (1932). Op. cit. (p. 12).

74 “Colegio de Nuestra Señora del Carmen”, en El Minero de Almagrera, $\mathrm{n}^{\mathrm{o}}$ 1.136, 12 de octubre de 1897, pp. 2-3. 
haberse erigido en centro generador de todo tipo de actos a los que solía acudir lo más relamido de la ya decadente sociedad cuevana. En la reputación alcanzada por la orden en el desempeño de su labor docente, en ese crédito que había trascendido más allá de los propios límites provinciales, en la categoría que había adquirido entre los pudientes, se fundamentó la dilatada trayectoria de los dominicos al frente de Ntra. Sra. del Carmen, superando el cambio de siglo y afianzándose hasta su marcha en 1919, cuando fueron relevados por los Hermanos de la Doctrina Cristiana.

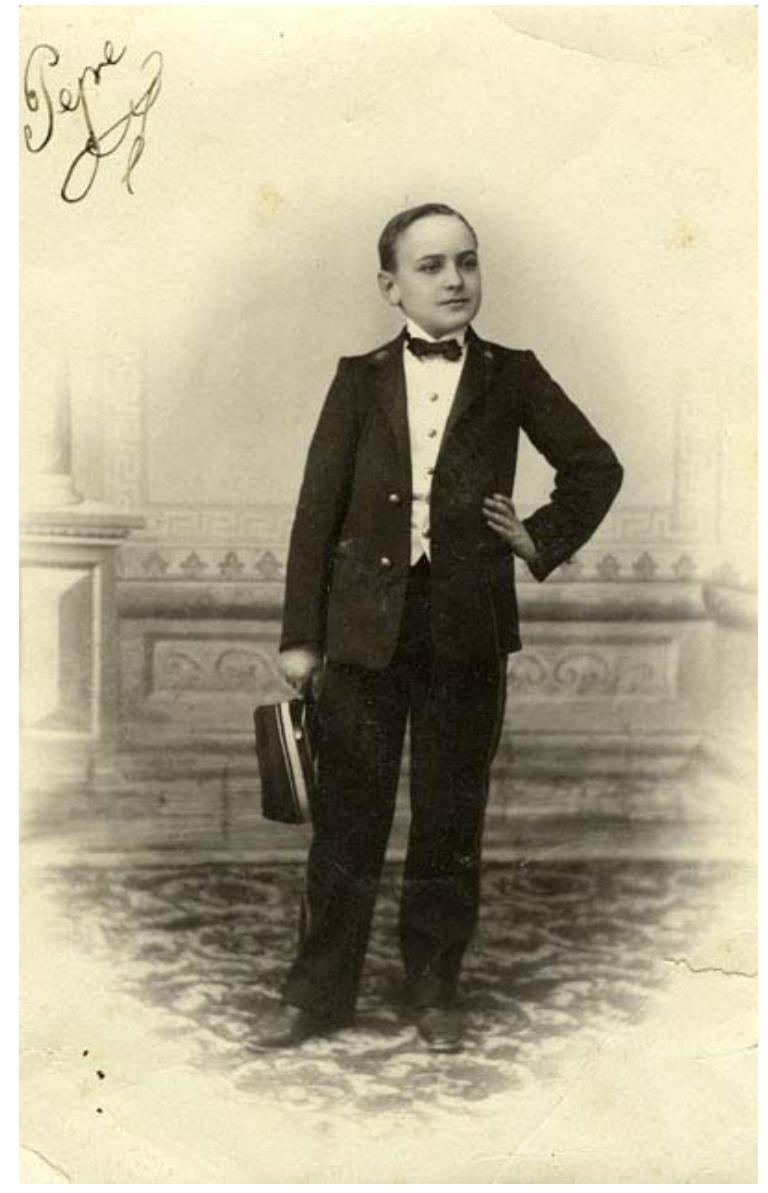

Figura 10.- Colegial de Nuestra Señora del Carmen con el uniforme estipulado por la dirección del centro. (Foto de Federico de Blain Becerra / Col. Enrique F. Bolea).

\section{4.- APÉNDICE DOCUMENTAL.}

Reglamento del Colegio de Ntra. Sra. del Carmen bajo la dirección de los PP. De la Orden de Predicadores (Dominicos).- Cuevas (Almería) (figura 11)

El año 1893 los PP. de la Orden de
Predicadores, invitados por el M. I. Ayuntamiento y principales propietarios de Cuevas, con la aprobación del Excmo. Sr. Obispo de la Diócesis, tomaron posesión del antiguo Colegio de Nuestra Señora del Carmen, con el objeto principal de procurar en él enseñanza sólida y educación religiosa a la juventud.

Para conseguir tan nobles fines y formar, no sólo hombres instruidos y religiosos, sino también caracteres firmes y elevados, se ejercerá sobre los alumnos una vigilancia continua, dulce y paternal; se excitará constantemente en sus almas una emulación saludable, fomentada por el premio al verdadero mérito; y se procurará arraigar en sus tiernos corazones la fe religiosa, el amor a la patria y el sentimiento de todos los deberes, que hacen del hombre digno y respetuoso por amor y convicción, no por temor o rutina.

El edificio está situado en una de las posiciones más bellas y saludables de la ciudad, y consta de hermosa Iglesia para el culto, espaciosos claustros, amplios e higiénicos salones de estudio, comedores, dormitorios muy ventilados, gabinetes de Física, Química, Historia Natural, Gimnasio, Biblioteca, Observatorio, patios de recreo y hermoso jardín botánico. Por

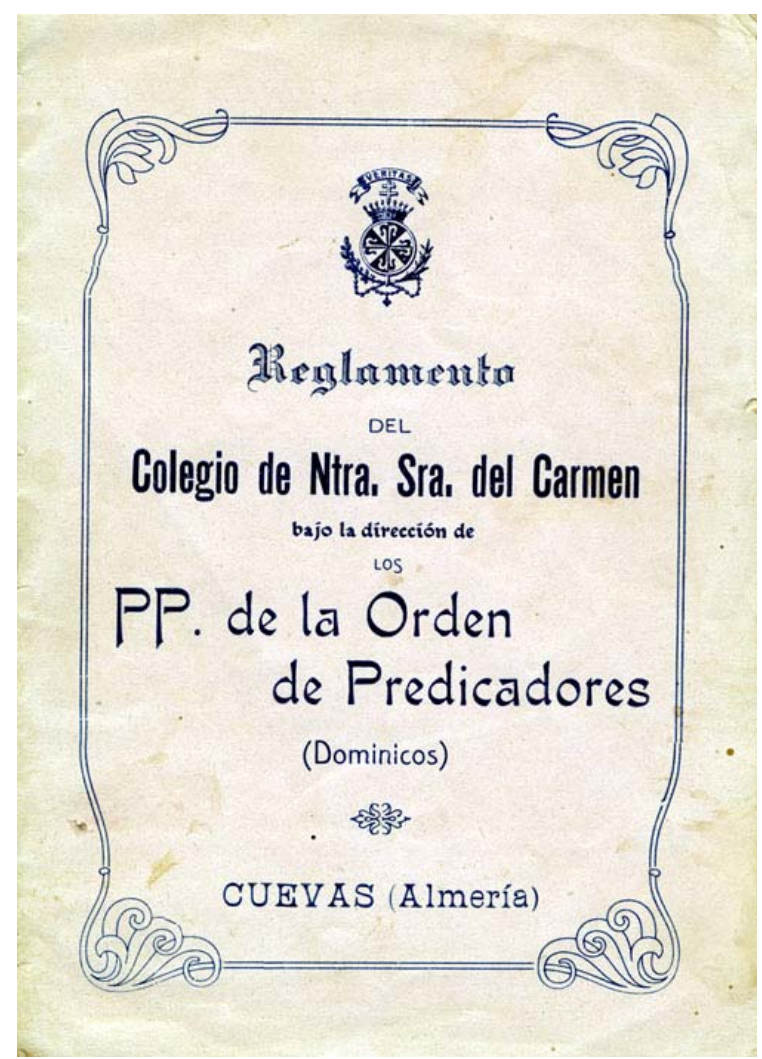

Figura 11.- Reglamento del Colegio de Ntra. Sra. del Carmen. 
lo cual figura con razón este Colegio entre los primeros de su clase.

\section{De la enseñanza.}

Artículo I. La enseñanza de este Colegio comprende las materias siguientes: a) Instrucción Primaria: elemental y superior, Lectura, Escritura, Catecismo, Gramática Castellana, Historia Sagrada y de España, elementos de Geografía y Matemáticas, y cuanto comprendan los programas oficiales de primera enseñanza; $b$ ) Segunda Enseñanza, hasta el Grado de Bachiller. La distribución por años y el orden de las asignaturas será con arreglo al plan vigente de estudios; c) Clases de Adorno: dibujo, piano, solfeo y gimnasia. A estas clases podrán asistir o no los alumnos, según la voluntad de sus padres o tutores, y el parecer del P. Rector.

Art. II. Habrá también clases obligatorias de Religión y Moral, Doctrina Cristiana y Urbanidad, en días y horas señaladas de antemano.

Art. III. El curso académico empieza el $1^{\circ}$ de Octubre y termina en Junio con los exámenes oficiales.

\section{De los alumnos internos.}

Artículo I. Los alumnos de este Colegio son de tres clases: internos, medio-internos y externos.

Art. II. Para la admisión de un alumno interno se necesita: a) Que sea mayor de 7 años y menor de 15 , a no ser que proceda de otro centro de enseñanza acreditado: $b$ ) Que los padres o tutores del niño pidan su admisión al rector del Colegio, expresando el nombre y apellidos, edad y estudios del aspirante: $c$ ) Que esté vacunado y no padezca enfermedad alguna crónica o contagiosa: d) Presentar la fe de bautismo, la cédula personal, si hubiere cumplido 14 años, o los cumpla antes del $1^{\circ}$ de Octubre y la certificación de los cursos académicos, si tuviese algunos aprobados.

Art. III. No podrá permanecer en el Colegio el alumno cuya conducta moral o académica exigiere de ordinario medios de rigor, o fuere perjudicial a los compañeros.

Art. IV. Siendo necesario que el Colegio matricule a todos sus alumnos que deseen ganar curso académico, se ruega a las familias que avisen antes del 30 de septiembre, indicando las asignaturas en que hayan de matricularse sus hijos.

Nota. Un aviso del P. Rector, dado anticipadamente a las familias, les hará saber el día en que deben llevar sus hijos al Colegio, como también el de la salida general de los alumnos.

\section{Del equipo.}

Artículo I. El equipo que deben presentar los alumnos, al ingresar en el Colegio, es el siguiente: a) Uniforme: traje completo de color negro, más un chaleco blanco de piqué, y gorra según modelo del Colegio: b) Dos trajes completos para diario y otro para los días festivos; tres pares de botas, uno por lo menos de color negro; tres blusas y algunas corbatas, dos de ellas una negra y otra blanca para el uniforme: c) Ropa interior: Cuatro camisas de plancha, dos de dormir, cuatro calzoncillos, diez pares de medias o calcetines, diez pañuelos de bolsillo, y el abrigo interior que gusten: $d$ ) Ropa de cama: Un colchón de lana de $180 \mathrm{cmo}$. de largo por 85 cmo. de ancho, cuatro sábanas, dos almohadas, cuatro fundas, dos mantas, dos sobrecamas blancas, una alfombrita para los pies y un saco para la ropa: e) Para la mesa y aseo: Un cubierto completo de metal blanco o plata meneses y un vaso y servilletero del mismo metal, cuatro servilletas, cuatro toallas, tijeras, cepillos y demás enseres de aseo: f) Un devocionario, las bulas de cruzada y carne y un librito de urbanidad que se proporcionará en el Colegio.

Todos los objetos de que se habla en este artículo deben estar marcados con las iniciales del alumno y el número que se le señalará al ser admitido en el Colegio.

Art. II. No se permite a los alumnos tener en su poder dinero, alhajas, instrumentos cortantes, etc., debiendo ser corregido el alumno a quien se le ocupare alguno de estos objetos.

\section{De la pensión.}

Artículo I. La pensión de los alumnos internos es de 250 pesetas cada trimestre, pagaderas anticipadamente en los meses de Octubre, Enero y Abril.

Art. II. En la mencionada pensión se comprenden, además de la manutención, la instrucción primaria, elemental y superior, la enseñanza de todas las asignaturas del Bachillerato, la de Religión y Moral y Urbanidad y el uso de la biblioteca, gabinetes y colecciones científicas.

Art. III. Serán de cuenta de los alumnos: a) Los libros de texto, matrículas y derechos de examen: b) Las clases de adorno: c) El lavado, planchado y compostura de ropa y calzado: d) Los gastos de escritorio y correspondencia: e) Cualquier otro 
gasto no comprendido en el artículo precedente.

Art. IV. Por la asistencia del médico, gastos de botica en enfermedades leves, servicio del barbero y uso de la cama somier, etc., cada alumno satisfará 10 pesetas anuales al ingreso.

Art. V. Los honorarios de las clases de adorno son: 10 pesetas las de piano y dibujo y 5 las de solfeo y gimnasia.

Art. VI. No se descontará nada del pupilaje por ausencias o demoras en la entrada, cuando son menores de un mes. En caso de salida definitiva el alumno tendrá derecho al reintegro de lo que hubiere pagado de más, excepto la cantidad correspondiente al mes comenzado y no concluido.

Art. VII. Cuando hubiere dos, tres o cuatro hermanos internos, podrá hacérseles, a petición de sus padres o tutores, una rebaja de 100, 375 o 750 pesetas respectivamente al comenzar el tercer trimestre.

\section{Visitas, salidas y comunicaciones.}

Artículo I. Los alumnos no recibirán más visitas que las de sus familias, o de las personas debidamente autorizadas por aquéllas, y esto en días festivos solamente y a las horas que el $\mathrm{P}$. Rector señale. La familia podrá, en casos urgentes, ver al alumno en cualquier día y hora, previa licencia del P. Rector.

Art. II. Los días festivos por la tarde, siempre que el tiempo lo permita, saldrán los colegiales a paseo por secciones y bajo la vigilancia de sus inspectores.

Art. III. Las familias de los alumnos, si residen en Cuevas, podrán sacarlos por la mañana y tenerlos en su compañía hasta la hora que se les señale el segundo Domingo de cada mes.

Art. IV. Los padres, abuelos o tutores y los parientes autorizados por escrito por aquéllos, si no residen en Cuevas, podrán sacar a sus hijos, nietos o pupilos en los mismos días y las mismas condiciones que se especifican en el artículo precedente. Esto mismo y en casos excepcionales, a juicio del Rector, podrán hacer también en días de clases, pero sólo después de haber cumplido el alumno con la última clase de la mañana hasta la primera de la tarde, en que debe continuar los ejercicios del horario interior del Colegio.

Art. V. Podrán los alumnos pasar las vacaciones de Navidad con sus familias, a condición de que éstas lo soliciten y el comportamiento reglamentario de los alumnos sea del todo satisfactorio.
Art. VI. Todas las semanas deberán los alumnos internos escribir a sus familias, entregando las cartas abiertas al P. Rector y recibiéndolas de él en la misma forma. Además de esto, el Colegio informará mensualmente a las familias sobre la conducta, aplicación y aprovechamiento de sus hijos, por medio de nota impresa que les será remitida.

Art. VII. Se prohíbe rigurosamente a todos los alumnos, de cualquiera clase que sean, dar o recibir cartas o encargos, de dentro para fuera o de fuera para dentro del Colegio, sin conocimiento y aprobación del P. Rector. La infracción se considerará como falta grave y como tal será castigada.

\section{Alimentación.}

Artículo único. La alimentación de los alumnos internos será sana, abundante y bien condimentada. Desayuno: chocolate, café con leche, leche sola, café solo o un huevo frito, a elección del alumno. Comida: sopa variada, dos platos fuertes, postres, y un vasito de vino. Merienda: un panecillo con dulce, fruta o cosa equivalente. Cena: sopa o legumbre, un plato fuerte, postre y vino.

No se permite a los alumnos recibir cosas de comer. Cualquier regalo que de esta clase se les hiciere se repartirá entre ellos y sus compañeros.

\section{Alumnos medio-internos.}

Artículo I. Se admiten medio-internos para la primera y segunda enseñanza.

Art. II. Estos alumnos entrarán en el Colegio a las 7 de la mañana y saldrán de él a las 7 de la tarde, siendo obligación de sus familias llevarlos y traerlos al Colegio.

Art. III. La pensión de los alumnos mediointernos será de 40 pesetas mensuales para los de primera enseñanza y de 55 para los de segunda, pagaderas anticipadamente.

Art. IV. En la mencionada pensión se comprenden: la comida y merienda, la enseñanza de todas las clases, excepto las de adorno, y el uso de aparatos y colecciones científicas. El trato y vigilancia de estos alumnos, mientras permanezcan en el Colegio, será en todo iguales a los de los externos.

\section{Alumnos externos.}

Artículo I. Los alumnos externos son de dos clases: de primera y de segunda enseñanza. Todos vivirán en casa de sus padres o en otra que merezca la confianza del Colegio. 
Art. II. Asistirán: a) A sus clases respectivas: $b$ ) A la misa solemne de días festivos: $c$ ) A todos los demás ejercicios académicos, piadosos o catequísticos que el Rector les señale.

Art. III. Los alumnos externos, además de los derechos de matrícula, exámenes, etc., satisfarán por mensualidades adelantadas 15 pesetas los de segunda enseñanza y 5 los de primera. Recibirán la segunda enseñanza gratuita siempre que presenten al Rector del Colegio certificación de pobreza, librada por los Sres. Párrocos y Alcalde de la ciudad.

\section{Adicional.}

Toda familia que ponga un niño en el Colegio, por el mismo hecho declara estar conforme con todos los artículos de este Reglamento.

\section{5.- REFERENCIAS BIBLIOGRÁFICAS.}

Colegio de Ntra. Sra. del Carmen (1894, 24 de junio). El Minero de Almagrera, 978, pp. 3.

Colegio de Nuestra Señora del Carmen en Cuevas (1897, 19 de septiembre). El Minero de Almagrera, 1.037.

Desagravio (1893, 27 de junio). El Minero de Almagrera, 930-931, pp. 4-5.

Discurso inaugural del Colegio de Nuestra Señora del Carmen de Cuevas (1893, pronunciado el 16 de octubre) por el M. R. P. Fr. Manuel Bada, de la orden de Predicadores. Cuevas: Est. Tip. de Serafín Campoy.

El Colegio de Cuevas (1894, 27 de septiembre). El Minero de Almagrera, 989-990, pp. 2-3.

Fausto acontecimiento. Inauguración del Colegio de Ntra. Sra. del Carmen (1881, 21 de octubre). El Minero de Almagrera, 371, pp. 1-2.

Fernández Bolea, E. \& Flores García, A. (2007). El teatro Echegaray de Cuevas del Almanzora, templo burgués de ocio y cultura. Axarquía, 12, 126.

Fernández Bolea, E. (1999). Colaboraciones literarias de Miguel Molina Valero en El Minero de Almagrera. Axarquía, 4, 206-213

Fernández Bolea, E. (2006). Agua y vida en Cuevas del Almanzora. Una historia de luchas y anhelos. (Siglos XVI - XXI). Cuevas del Almanzora: Arráez Editores.

Fernández Bolea, E. (2006). Molina Valero, Miguel. En J. P. Díaz López (coor.), Diccionario biográfico de Almería (p. 259). Almería: Instituto de Estudios Almerienses y Cajamar.
Flores González-Grano de Oro, M. (1932). Las instituciones escolares de Cuevas del Almanzora (Almería). Cuevas: Imprenta de Campoy.

Flores González-Grano de Oro, M. (1932, 30 de noviembre). Las Instituciones escolares en Cuevas del Almanzora (Almería). El Censor, 85, 1-2.

Gran acuerdo (1878, 22 de junio). El Minero de Almagrera, 209, pp. 1-2.

Grima Cervantes, J. \& Fernández Bolea, E. (2004). Baria: una ciudad de la Antigüedad clave para entender nuestro pasado y trascendental como pilar del patrimonio histórico y arqueológico de la Axarquía almeriense. Axarquía, 9.

Grima Cervantes, J. (Coord.) (1996). En A, Alarcón, A. \& J. Alarcón, Turre. Historia, cultura, tradición y fotografía (pp. 61-62). Turre: Arráez Editores.

Instrucción pública (1880, 8 de mayo). El Minero de Almagrera, 301, pp. 1-2.

La inauguración del Colegio el día 16 de octubre (1893, 16 de octubre). El Minero de Almagrera, 945, pp. 2-4.

Las escuelas de Cuevas (1880, 19 de mayo). El Minero de Almagrera, 302, p. 3.

Madoz, P. (1845-1850). Diccionario geográficoestadístico-descriptivo de España y sus posesiones de ultramar. Madrid. (Publicado en edición facsímil en Valladolid: ÁmbitoEditoriales Andaluzas Unidas, 1988).

Martínez Navarro, P. E. (2007). Semblanzas, perfiles y notas biográficas de cuevanos y cuevanas ilustres ( $2^{\mathrm{a}}$ ed.). Cuevas del Almanzora: Ayto de Cuevas del almanzora. Arráez Editores.

Molina Sánchez, A. (1990). El libro de Cuevas del Almanzora hace un siglo. Almería: Ayto de Cuevas del Almanzora.

Reglamento del Colegio de Ntra. Sra. del Carmen bajo la dirección de los PP. de la Orden de Predicadores (Dominicos). Cuevas (Almería), [s. a.].

Publicaciones periódicas:

- El Minero de Almagrera

- El Censor

Fuentes archivísticas:

- Archivo Municipal de Cuevas del Almanzora 